\title{
A Hydro-Economic Approach to Representing Water Resources Impacts in Integrated Assessment Models
}

Paul H. Kirshen, Co-Principal Investigator

Civil and Environmental Engineering Department, and Water, Sustainability, Health, and Ecological Diversity (WaterSHED) Center, Tufts University, Medford MA 02155

Kenneth M. Strzepek, Co-Principal Investigator

Department of Civil, Environmental and Architectural Engineering, and Environment and Behavior Program, Institute for Behavioral Science, University of Colorado, Boulder, CO 80309

With contributions from

$$
\begin{gathered}
\text { Trace Bundy } \\
\text { Brent Butzin } \\
\text { Ximing Cai } \\
\text { Gunther Fischer } \\
\text { David Major } \\
\text { Alyssa McCluskey } \\
\text { Mark McCluskey } \\
\text { Mark Rosegrant } \\
\text { Richard Vogel } \\
\text { Dave Wiberg } \\
\text { David Yates } \\
\text { Gary Yohe }
\end{gathered}
$$$$
\text { January 14, } 2004
$$

Final Report

Grant Number DE-FG02-98ER62665

Office of Energy Research of the U.S. Department of Energy 


\begin{abstract}
Many Integrated Assessment Models (IAM) divide the world into a small number of highly aggregated regions. Non-OECD countries are aggregated geographically into continental and multiple-continental regions or economically by development level. Current research suggests that these large scale aggregations cannot accurately represent potential water resources-related climate change impacts. In addition, IAMs do not explicitly model the flow regulation impacts of reservoir and ground water systems, the economics of water supply, or the demand for water in economic activities.

Using the International Model for Policy Analysis of Agricultural Commodities and Trade (IMPACT) model of the International Food Policy Research Institute (IFPRI) as a case study, this research implemented a set of methodologies to provide accurate representation of water resource climate change impacts in Integrated Assessment Models. There were also detailed examinations of key issues related to aggregated modeling including: modeling water consumption versus water withdrawals; ground and surface water interactions; development of reservoir cost curves; modeling of surface areas of aggregated reservoirs for estimating evaporation losses; and evaluating the importance of spatial scale in river basin modeling.
\end{abstract}

The major findings include:

- Continental or national or even large scale river basin aggregation of water supplies and demands do not accurately capture the impacts of climate change in the water and agricultural sector in IAMs.

- Fortunately, there now exist gridden approaches ( $0.5 \mathrm{X} 0.5$ degrees) to model streamflows in a global analysis. The gridded approach to hydrologic modeling allows flexibility in aligning basin boundaries with national boundaries. This combined with GIS tools, high speed computers, and the growing availability of socio-economic gridded databases allows assignment of demands to river basins to create hydro-economic zones that respect as much as possible both political and hydrologic integrity in different models.

- To minimize pre-processing of data and add increased flexibility to modeling water resources and uses, it is recommended that water withdrawal demands be modeled, not consumptive requirements even though this makes the IAM more complex.

- IAMs must consider changes in water availability for irrigation under climate change; ignoring them is more inaccurate than ignoring yield changes in crops under climate change.

- Determining water availability and cost in river basins must include modeling streamflows, reservoirs and their operations, and ground water and its interaction with surface water. 
- Scale issues are important. The results from condensing demands and supplies in a large complex river basin to one node can be misleading for all uses under low flow conditions and instream flow uses under all conditions. Monthly is generally the most accurate scale for modeling river flows and demands. Challenges remain in integrating hydrologic units with political boundaries but the gridded approach to hydrologic modeling allows flexibility in aligning basin boundaries with political boundaries.

- Using minimal reservoir cost data, it is possible to use basin topography to estimate reservoir storage costs.

- Reservoir evaporation must be considered when assessing the usable water in a watershed. Several methods are available to estimate the relationship between aggregated storage surface area and storage volume.

- For existing or future IAMs that can not use the appropriate aggregation for water, a water preprocessor may be required due the finer scale of hydrologic impacts.

\subsection{Introduction}

Many Integrated Assessment Models (IAM) divide the world into a small number of highly aggregated regions. Non-OECD countries are aggregated geographically into continental and multiple-continental regions or economically by development level. Current research suggests that these large-scale aggregations cannot accurately represent potential water resources-related climate change impacts. In addition, IAMs do not explicitly model the flow regulation impacts of reservoir or ground water systems, the economics of water supply, or the demand for water in economic activities.

Using the International Model for Policy Analysis of Agricultural Commodities and Trade (IMPACT) of the International Food Policy Research Institute (IFPRI), this research implemented a set of methodologies to provide accurate representation of water resources climate change impacts in IAMs. These are Sections 2.0 and 3.0 of the report. These are followed by summaries of analyses of various issues related to aggregated modeling which informed much of the addition of water resources to IAMs. Full papers on these topics are also available. These important aspects include:

- Explicit Consideration of Consumption, Groundwater, and Instream Flow Needs: A Case Study of China

Developing Reservoir Cost Curves: A Case Study of China

- Modeling of Surface Areas of Aggregated Reservoirs for Estimating Evaporation Losses

- Evaluating Importance of Spatial Scale in River Basin Modeling: A Case Study of Missouri River Basin 
To meet the objectives of this research, we partnered with several other related research activities. These included:

- International Institute for Applied Systems Analysis (IIASA) Land Use and Global Change Project

- Integrated Assessment of the Impacts of Climate Change and Variability on Global Water and Food Systems Project of IFPRI and the International Water Management Institute (IWMI) as part of the ADAPT Multi-scale Agriculture and Water Climate Impacts and Adaptation project executed by Institute for Environmental Studies, Free University of Amsterdam, as part of the larger Dialogue on Water and Climate Project, funded by the government of Netherlands.

- Integrated Climate Change and Human Impacts Project, Center for Integrated Study of the Human Dimensions of Global Change at Carnegie Mellon University

The report concludes with related modeling implementation results.

\subsection{Estimating Monthly Time Series of River Basin Runoff}

Since different IAMs disaggregate the world into different subregions, maximum flexibility is obtained if water resources modeling is initially done at relatively fine scale. The river basin runoff model (WATBAL) applies a gridded approach to compute water balances for each of the $0.5^{\circ} \times 0.5^{\circ}$ land surface grids of the Climate Research Unit of the University of East Anglia climate dataset (Viner, 2000). In addition to the land surface mask, a $0.5^{\circ} \times 0.5^{\circ}$ mask that corresponds to the major hydro-economic river basins of an IAM is also defined, and is used to accumulate the runoff from each $0.5^{\circ} \times 0.5^{\circ}$ grid cell of the land mask to represent total basin streamflow. A GIS program extracts the runoff and precipitation values and aggregate the grids into the IMPACT subregions or spatial units.

The hydrologic model consists of a conceptually simple, one-dimensional vertical water balance model that incorporates a soil moisture accounting scheme based on empirical functions that describe evapotranspiration, and surface and sub-surface runoff. The model is described in detail in Yates (1996). A temperature-index, snowmelt model is used to track snow accumulation and melt over those cells with temperatures that fall below a threshold corresponding to rain changing to snow. Actual evapotranspiration is a function of the relative soil moisture of the one-dimensional 'bucket' and the total potential evapotranspiration (PET) that is computed based on the classical PenmanMontieth model. Figure 2.1 shows the components of the conceptual water balance model that allows for the characterization of land use specific impacts on runoff. Since this is a monthly runoff model, river routing is not considered, but for larger basins, there can be a one-month lag associated with the sub-surface runoff. 


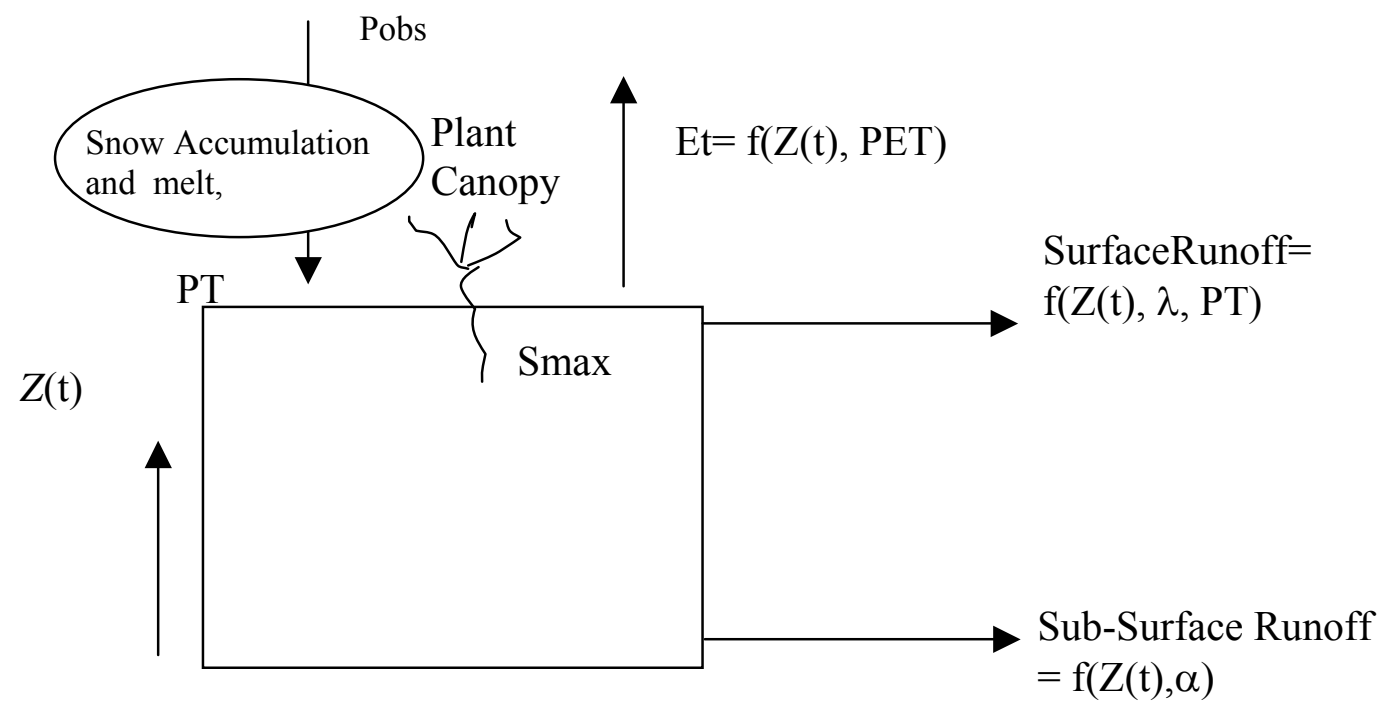

Figure 2.1 Schematic of Soil Moisture Scheme for Generation of Basin Runoff and Potential Evapotranspiration.

The uniqueness of this gridded water balance model is in its use of continuous functions of relative storage to represent surface and sub-surface runoff and evapotranspiration in the form of a differential equation (Yates, 1996).

The monthly soil moisture balance is written as:

$S_{\max } d Z / d t=P T-R_{s}(P T, Z(t), t)-R_{s s}(Z(t), t)-\operatorname{Et}(P E T, Z(t), t)$

Where

PET = potential evapotranspiration

Pobs = measured precipitation 


$$
\begin{array}{ll}
\mathrm{PT} & =\text { total effective precipitation } \\
\mathrm{R}_{\mathrm{S}} & =\text { surface runoff } \\
\mathrm{R}_{\mathrm{ss}} & =\text { sub-surface runoff } \\
\mathrm{Et} & =\text { actual evaporation } \\
\mathrm{Z}(\mathrm{t}) & =\text { relative Storage }
\end{array}
$$


The monthly water balance contains parameters related to surface runoff $(\lambda)$ and subsurface runoff ( $\alpha, \mathrm{mm} / \mathrm{month})$. A third model parameter, maximum catchment soil moisture holding capacity $\left(\mathrm{S}_{\max }\right)$ is obtained from the global dataset of Dunne and Willmott (1996). The total effective precipitation (PT) is the amount of water entering the storage zone after losses or contributions from snowmelt accumulation and melt are considered. Eq 3.1 is solved for each month for $\mathrm{z}(\mathrm{t})$ using numerical methods.

The model is calibrated to historic data adjusted for anthropogenic influences either by trial ands error or by a Genetic Algorithm.

\subsection{An Integrated Assessment of the Impact of Climate Change and Variability on the Global Water and Food Systems - Example Application of Water Resources in Integrated Assessment}

\section{Introduction}

This application of IMPACT with WATBAL was for the ADAPT project. Institutions contributing to this report included University of Colorado, Tufts University, National Center for Atmospheric Research, International Food Policy Research Institute, International Water Management Institute, and International Institute for Applied Systems Analysis.

\section{Policy Relevance}

According to a number of studies, in the coming decades global agriculture faces the prospect of a changing climate, which might affect meeting global food needs. The prospective climate change consists of global warming and associated changes in hydrological regimes and other climatic variables, such as higher temperatures, shorter growing seasons, changing moisture regimes, and extreme weather patterns. Global warming could have both negative and positive effects on agriculture. At higher latitudes, increased temperatures could lengthen the growing season and ameliorate cold temperature effects on growth. In warmer mid-latitude environments, adverse effects could include increased pests and crop diseases, soil erosion, increased flooding, desertification and reduced water resources for irrigation. Despite many studies, there is no consensus on the magnitude, nature, and time horizon of possible changes and related effects on agriculture.

The key questions that were addressed in this research are:

- What are the impacts of a changing climate and climate variability on water scarcity, food production and food security?

- What is the role of international food trade in mitigating food scarcity as the result of a changing climate and climate variability? 


\section{Approach}

Yates and Strzepek (1998) have shown for Egypt that the national economic impacts from changes in world market prices due to global climate impacts are of equal magnitude to the local climate change impacts of reduced Nile flow, decreased crop yields, and land loss due to sea-level rise. Drawing on the results in Egypt, it is useful to also examine the global perspective. Fischer et al. (1988), Rosenweig and Parry (1994), and Rosegrant,et al. (1995) have done global food assessments but did not include information on water resources. This Global Scale Analysis interacts with the River Basin case studies as illustrated in Figure 3.1
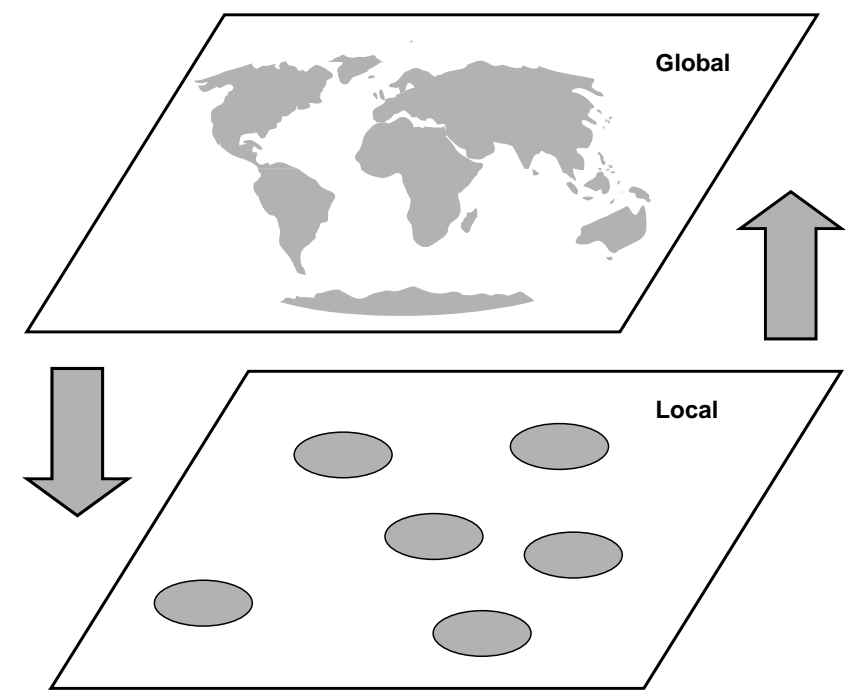

Figure 3.1 Strategic cyclical scaling: Evaluation at local and global scales (from Root and Schneider, 1995).

\section{Methodology}

At the global level an integrated assessment methodology based on state of the art economic, hydrologic, agricultural, and environmental system models was developed.

The models are:

1. The Global Agro-Ecological Zones (GAEZ) model to provide a standardized framework for the characterization of climate, soil, and terrain conditions relevant to agricultural production developed by the International Institute for Applied System Analysis.

2. The IFPRI IMPACT model enhanced with water as an input.

3. The K-nn Monthly Conditional Surface Climate Generator developed at National Center for Atmospheric Research and University of Colorado

Figure 3.2 summarizes the overall approach used in this integrated global analysis of the impacts of climate change and climate variability on the availability and use of water and 
the production and consumption of food. The GAEZ model provides a standardized framework for the characterization of climate, soil and terrain conditions relevant to agricultural production, particularly to estimate maximum potential crop yield in a gridded format that can be used by IMPACT. In GAEZ, crop modeling and environmental data are used to identify crop-specific limitations due to climate, soil, and terrain under assumed levels of inputs and management conditions.

Hereafter, the IMPACT-FOOD and IMPACT-WATER models are referred to as IMPACT. IMPACT is a representation of a competitive world agricultural market for crops and livestock. It is specified as a set of country or regional submodels. Within each submodel, supply, demand, and prices for agricultural commodities are determined. IMPACT also assumes crop yield increases due to technological advances. The country and regional agricultural submodels are linked through trade, which highlights the interdependence of countries and commodities in the global agricultural markets. World agricultural commodity prices are determined annually at levels that clear international markets. In IMPACT, water is represented as a scarce resource needed for agricultural production. IMPACT performs a simplified river basin water balance by taking into account storage, and groundwater and interbasin transfers. Water demands include irrigation, livestock, domestic and industrial demands, and committed instream flow for environmental, ecological, and navigational uses.

The global hydrology model described in Section 2.0 produces river basin runoff over a 30 -year time horizon on a monthly time step. The river basin runoff data are used by IMPACT to define the water supply for each of the IMPACT hydro-economic zones (described subsequently). Reservoir storage in each of the 69 zones is taken from existing data, and assumptions are made about growth in storage over the planning horizon. Ground water availability is limited to an exogenously entered sustainable withdrawal independent of climate change. The price of water is exogenously entered based upon historic rates of change and then estimated elasticity's are used to determine unit water demands for the nonagricultural sectors. These demands coupled with the sizes of the nonagricultural sectors are then used to calculate the total nonagricultural demands. PET is used to estimate agricultural demands. In Section 4.0, we summarize how groundwater can be endogenous to an IAM.

Although the IMPACT model will account for autonomous adaptation, IMPACT is also capable of describing the response of global water use and food production to exogenous adaptation strategies such as improved irrigation efficiency, changes in farm subsidies, capital investments, etc, via policy options or parametric analysis. These external or exogenous variables are prescribed, and comprise individual scenarios whose results are examined relative to baseline, non-exogenously driven scenarios. For this study, we have only focused upon autonomous adaptations, with the hopes of extending the work to include scenarios of explicit, exogenous adaptation strategies in the future. 
The GCM's (Global Circulation Models) used in this analysis to provide precipitation and temperature for climate change scenarios include the Max Plank Institute Models ECHAM4 B2 2020 and B2 2080 and the Hadley Center Models HadCM3 A1 2020, A1 2080, B2 2020, and B2 2080. 


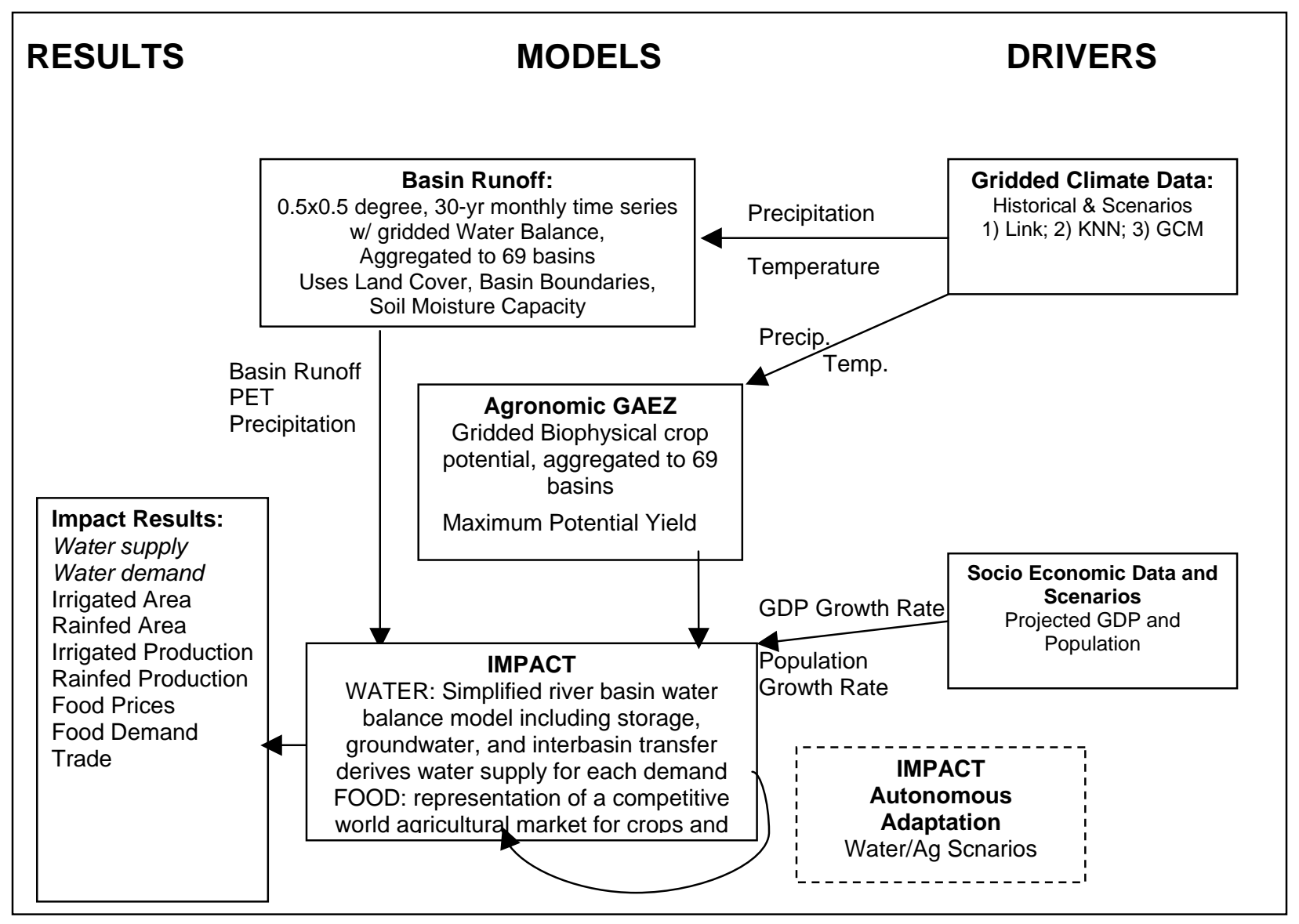

Figure 3.2 Overview of study components.

In addition to GCM based climate scenarios, we developed a statistical technique to derive new scenarios based on changes in the occurrence of the El-Niño, Southern Oscillation phenomenon (ENSO). ENSO are sea-surface temperature anomalies that occur periodically off the western coast of South America, with a seasonal timescale. When sea-surface temperatures are above normal the condition is referred to as El Niño, while the sea-surface temperatures are below normal, the condition is called La Niña.

Alternative climate scenarios allow us to systematically investigate the impacts of different global climate regimes (such as increased occurrence of ENSO years) on food production. To develop these scenarios, we employed a modified version of the K-nearest neighbor (K-nn) algorithm of Lall and Sharma (1996), Rajagopalan and Lall (1999), and Buishand and Brandsma (2001) to generate monthly time series of basin climate data, conditioned on the ENSO index. Essentially, the K-nn method is a strategic resampling of historical precipitation and temperature data to derive new climate series. 


\section{IMPACT Regions and Basins and ADAPT Basins}

One of the constraints in this analysis is the restriction of specifying basin boundaries. The IMPACT model divides the world into 69 broad hydro economic regions with three of these regions (the United States, China and India) more finely divided by their major river basins. These basins and regions (Figure 3.3) were developed specifically for global scale food policy assessments and it was beyond the scope of this work to modify the regions to exactly match the ADAPT basins in Figure 3.4. The seven ADAPT case study basins were mapped to the IMPACT basins/regions (Figure 3.4). The basin representation is more acceptable in regions that are fairly homogeneous and small. Some basins were split over more than one region, for example the Volta was split between Northern Africa and Central and Western Africa. It was the authors' discretion how to associate the regions and basins. Throughout the results section when data refers to one of the seven ADAPT basins, it is actually referring to the IFPRI basin/regions that contain that basin.

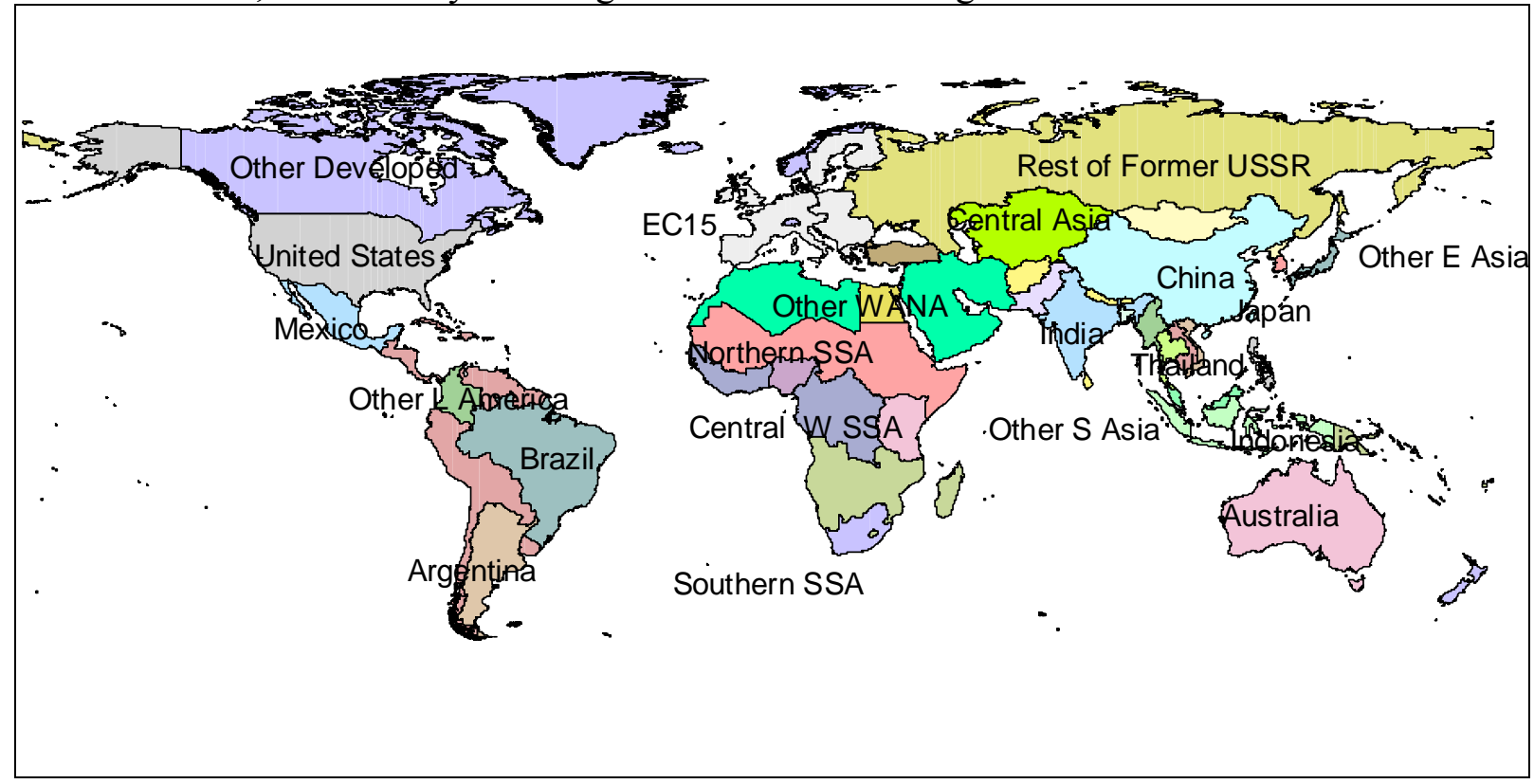

Source: Authors' assessments.

Figure 3.3 IMPACT Basins 


\section{ADAPT RIVER BASINS}

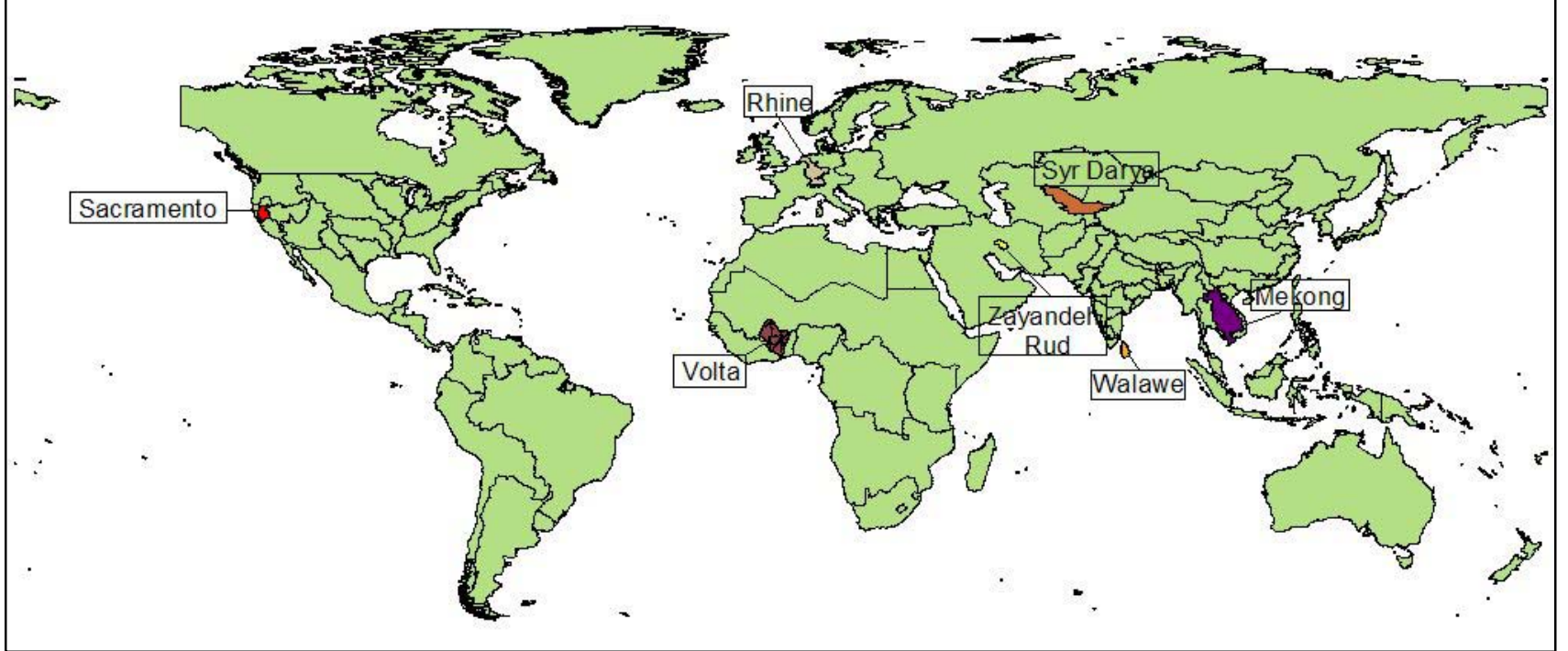

Figure 3.4 Mapping IFPRI basin/regions to ADAPT basins

\section{Results and Analysis}

\section{GAEZ Results}

Figures 3.5 and 3.6 present the change in the maximum potential yields without water stress due to climate change for rice and wheat, respectively. The yield changes are the result of the changed level and timing of the thermal conditions in the regions with $\mathrm{CO} 2$ fertilization taken into account (on average a 35\% increase in rice yield and a $20 \%$ decrease in wheat yield for the ADAPT basins). A corresponding increase of potential and actual evapotranspiration will take place.

For rice yields the basins fall into three distinct groups. Group one, the Walawe, Rhine and Sacramento show increase of potential yields under all climate change scenarios. Group two, the Volta, Zayandeh Rud, and Mekong all show a decrease of potential yields under all climate change scenarios. The remaining basin, the Syr Darya increases for 5 of the 6 climate change scenarios, but decreases for the 2080 A1 Hadley. All changes are due to changes in the temperature distribution over the year and the $\mathrm{CO} 2$ fertilization effects.

A different picture is seen for wheat where only the Rhine shows increased yields for all scenarios while the Sacramento increased for 5 of the 6 scenarios with the only decrease being for the 2080 A1 Hadley, similar to the Syr Darya for rice. The remaining basins all show decreases. 
These results all follow agronomic principles. For rice, a warm climate crop, yields increase in the cooler basins. For wheat, a temperate climate crop, most ADAPT basins (semi-arid or tropical) observe a decrease in yields as the areas get warmer.

\section{IMPACT-WATER Results}

The hydro-climatic variables (potential evapotranspiration, effective precipitation (this is different from the effective precipitation in the monthly runoff model described in Section 2.0; here it is the precipitation actually available for crops), crop water deficit, and available water for irrigation, termed available water) are presented for the globe as a simple indicator even though there are significant spatial scales differences. These variables are also presented separately for the developed and developing regions of the world. Finally to provide results at the local geographical scale, these variables are presented for the seven IMPACT-WATER basins associated with the ADAPT river basins.

Figure 3.7 shows that globally there is very little change from the base conditions for actual crop evapotranspiration, effective precipitation, and water deficit. There is a slight increase in water available for irrigation from reservoirs. This results show that irrigated agriculture will be impacted more than rainfed agricultural.

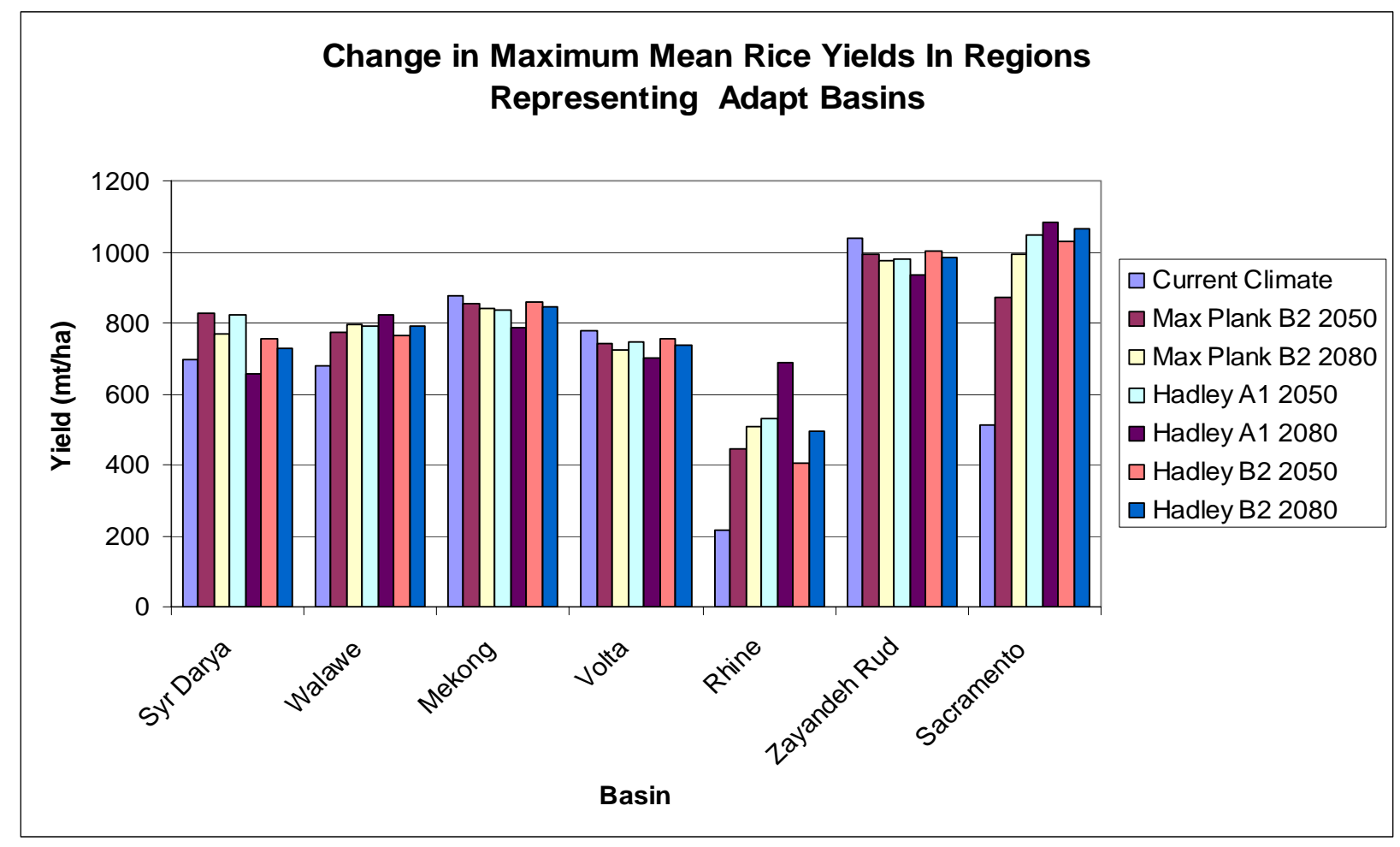

Figure 3.5 Change in maximum rice yields in regions representing adapt basins 


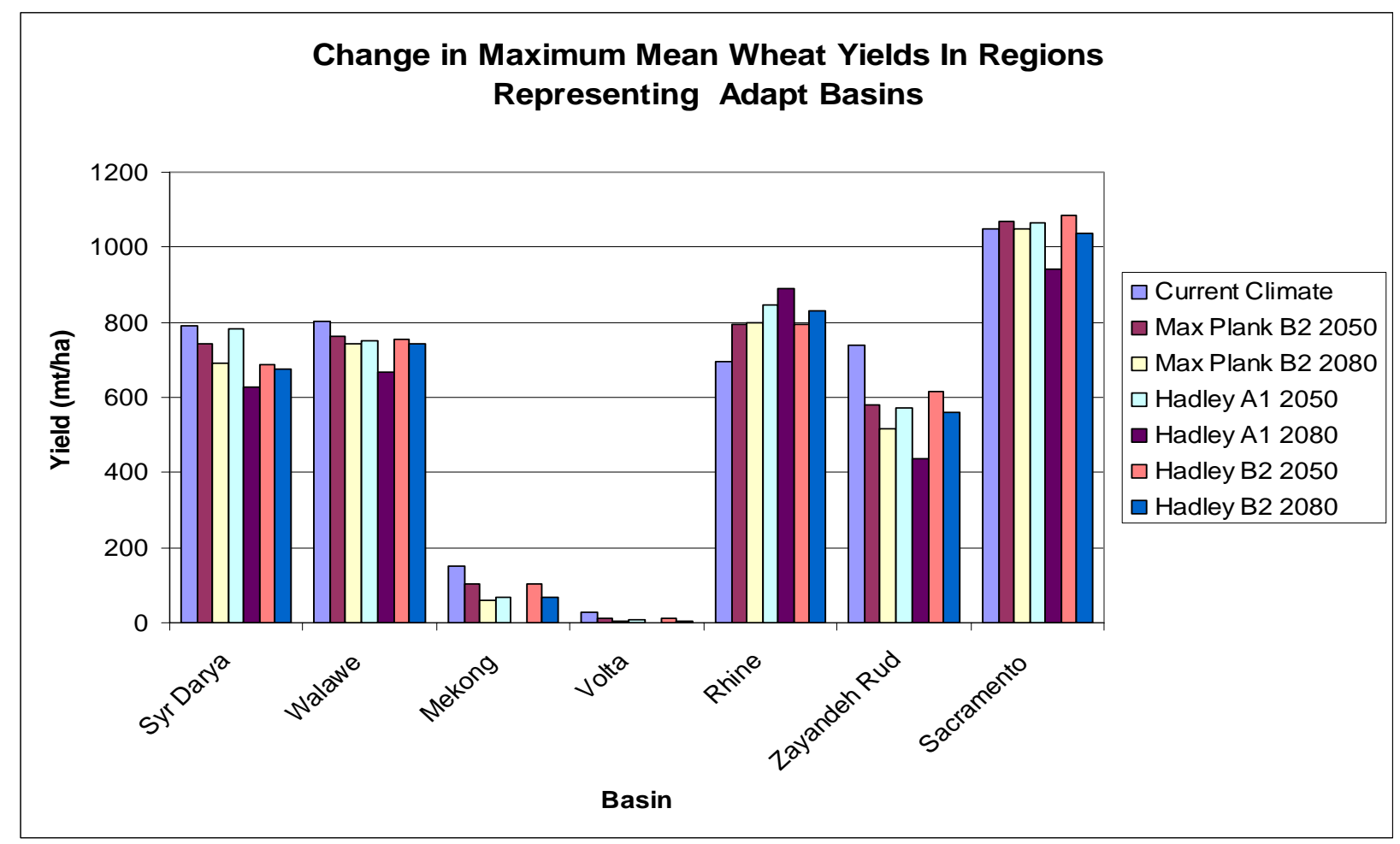

Figure 3.6 Change in maximum wheat yields in regions representing adapt basins

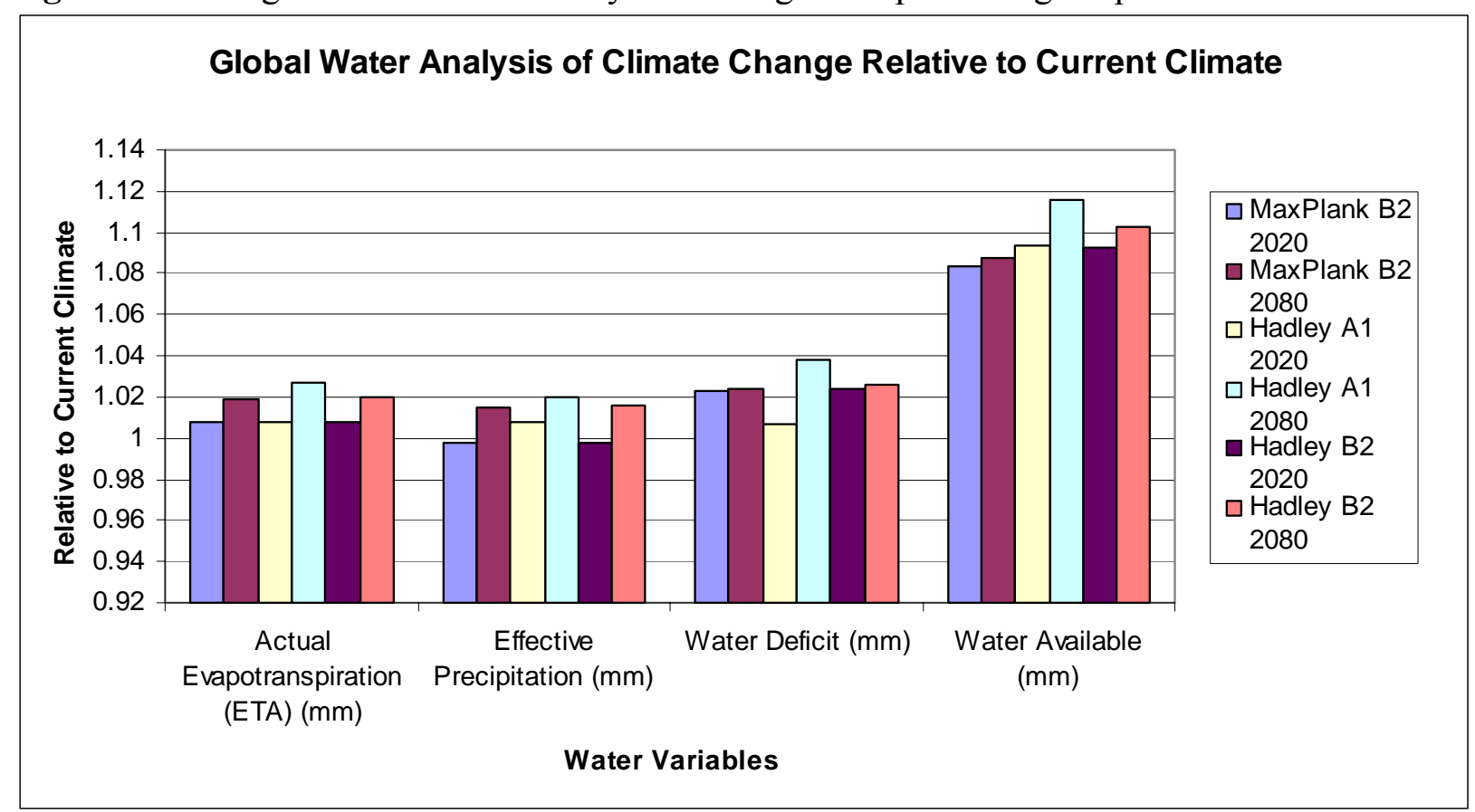

Figure 3.7 Global Water Analysis of Climate Change Relative to Current Climate 


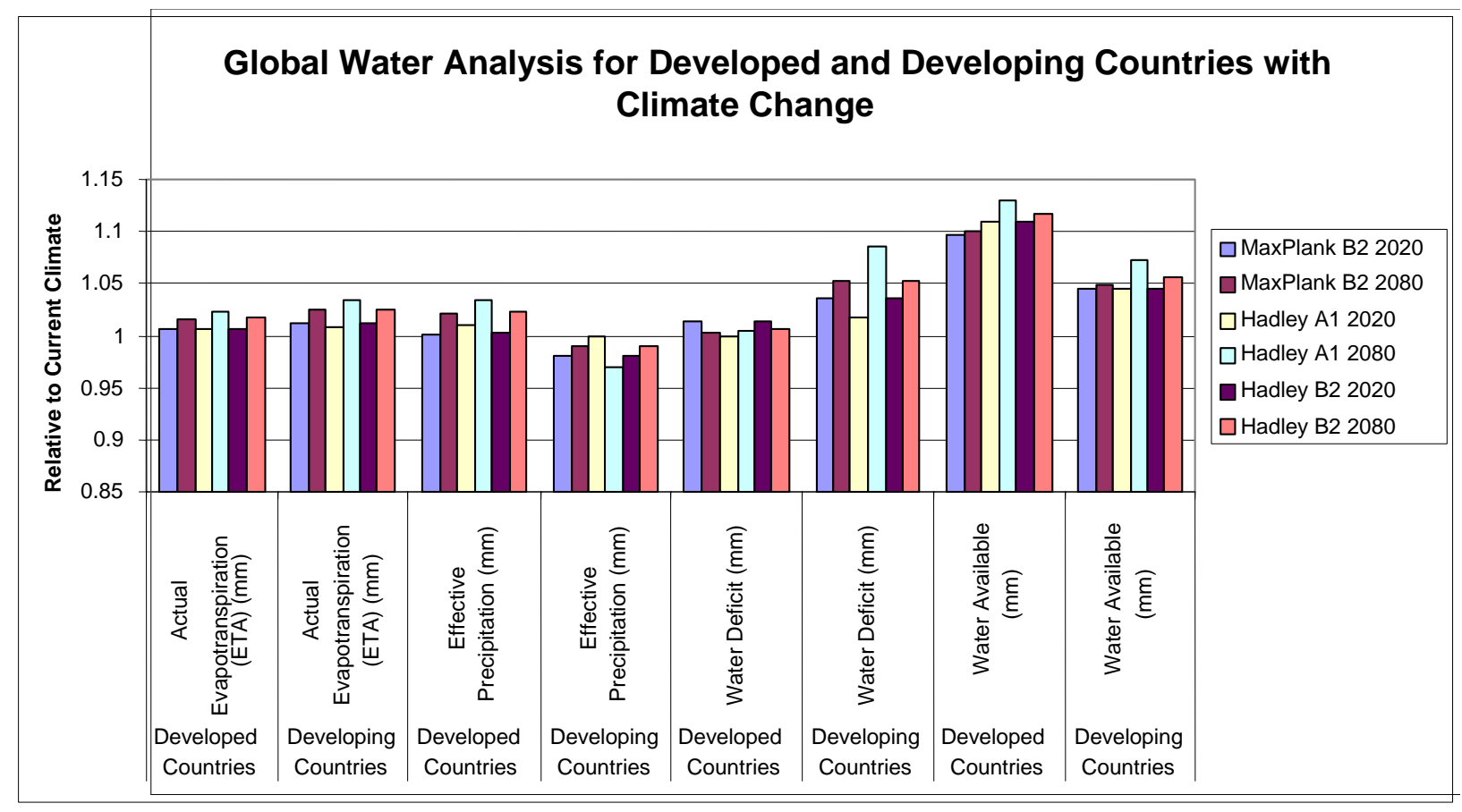

Figure 3.8 Global Water Analysis for Developed and Developing Countries with Climate Change

The results in Figure 3.8 for developed and developing regions illustrate the difference between the predominately humid developed countries and the predominately semiarid/arid developing countries. The results show that the developing regions are more strongly impacted. There is a greater decrease in effective precipitation and a greater increase in water deficit.

Table 3.1 presents the results for the seven adapt basins as calculated using the IFPRI basin/regions. As stated and illustrated above, the IFPRI basin/regions are highly aggregated and many times span hydro climatic zones. These detailed regional results should only be viewed to illustrate the geographical variation in climate change results as they do not accurately represent the named basins due to GCM and IFPRI basin scales. What the table does illustrate is that climate change can have mitigating or multiplicative effects on agricultural water balances in a region. For example, the Sacramento Basin has water availability going up, but water deficit going up as well. Thus the final impact on food production can only be seen from the food model results. For the Syr Darya, Mekong, and Walawe basins decreases in water availability lead to a reduction in the water provided to the crops via irrigation so the water deficit is increased.

\section{IMPACT-FOOD Results}

\section{Mean Value Climate Change}

The model is driven not only by climate by also by socio-economic and the associated technological changes. Thus as seen in Figure 3.9 the prices of wheat decline from 2000 
to 2025 as the economic impacts of yield increase is felt by the system. Note however that the climate change scenarios preserve this trend but impact the level of final prices. Globally, the climate factors of production of wheat are enhanced by climate change and this leads to lower world market prices. However, within regions, there can be the opposite effect.

This same phenomenon is illustrated in Figure 3.10 which shows an increase in global food demand as the result of increased population and lower prices. Climate change again impacts the rate and level of this increased demand by reduced global prices.

When looking at food production and demand in developed and developing countries, one can see that climate change will affect the countries differently (Figure 3.11) Irrigated and rainfed production will increase more in developed versus developing countries. Rainfed production is actually decreasing slightly in developing countries with some climate change scenarios. This may lead to more poverty relative to the developed nations as poorer farmers rely on rainfed agriculture to grow their crops. If rainfed production decreases, farmers that cannot afford irrigation will be hurt the most. When it comes to food demand, both developed and developing countries show the same trend of slightly increasing demand. IMPACT -WATER assumes that consumers will have the income to purchase low price imported food. For the low-income consumers, especially urban poor, this assumption may not hold and reduced production may not be made up for by purchases of imports and thus hunger will increase.

Table 3.1 Water Resource Results for ADAPT RIVER BASINS (percent changes from present conditions)

\begin{tabular}{|c|c|c|c|c|c|c|c|}
\hline & \multicolumn{7}{|c|}{ Actual Evapotranspiration (ETA) } \\
\hline & Sacramento & Rhine & Syr Darya & Volta & $\begin{array}{l}\text { Zayandeh } \\
\text { Rud }\end{array}$ & Walawe & Mekong \\
\hline $\begin{array}{l}\text { MaxPlank B2 } \\
2020\end{array}$ & $1 \%$ & $3 \%$ & $2 \%$ & $1 \%$ & $1 \%$ & $1 \%$ & $0 \%$ \\
\hline $\begin{array}{ll}\text { MaxPlank } & \text { B2 } \\
2080 & \\
\end{array}$ & $2 \%$ & $6 \%$ & $4 \%$ & $2 \%$ & $2 \%$ & $2 \%$ & $1 \%$ \\
\hline Hadley A1 2020 & $1 \%$ & $2 \%$ & $1 \%$ & $1 \%$ & $1 \%$ & $1 \%$ & $1 \%$ \\
\hline Hadley A1 2080 & $3 \%$ & $6 \%$ & $4 \%$ & $3 \%$ & $2 \%$ & $2 \%$ & $2 \%$ \\
\hline Hadley B2 2020 & $1 \%$ & $2 \%$ & $1 \%$ & $1 \%$ & $1 \%$ & $1 \%$ & $1 \%$ \\
\hline \multirow[t]{3}{*}{ Hadley B2 2080} & $2 \%$ & $4 \%$ & $3 \%$ & $2 \%$ & $1 \%$ & $2 \%$ & $2 \%$ \\
\hline & \multicolumn{7}{|c|}{ Effective Precipitation } \\
\hline & Sacramento & Rhine & Syr Darya & Volta & $\begin{array}{l}\text { Zayandeh } \\
\text { Rud }\end{array}$ & Walawe & Mekong \\
\hline $\begin{array}{ll}\text { MaxPlank } & \text { B2 } \\
2020 & \\
\end{array}$ & $-10 \%$ & $5 \%$ & $4 \%$ & $3 \%$ & $-6 \%$ & $1 \%$ & $1 \%$ \\
\hline $\begin{array}{ll}\text { MaxPlank } & \text { B2 } \\
2080 & \end{array}$ & $-14 \%$ & $11 \%$ & $8 \%$ & $3 \%$ & $-9 \%$ & $3 \%$ & $2 \%$ \\
\hline Hadley A1 2020 & $-9 \%$ & $1 \%$ & $8 \%$ & $1 \%$ & $0 \%$ & $1 \%$ & $1 \%$ \\
\hline Hadley A1 2080 & $-17 \%$ & $8 \%$ & $1 \%$ & $3 \%$ & $-16 \%$ & $2 \%$ & $3 \%$ \\
\hline
\end{tabular}




\begin{tabular}{|c|c|c|c|c|c|c|c|}
\hline Hadley B2 2020 & $-10 \%$ & $5 \%$ & $4 \%$ & $3 \%$ & $-6 \%$ & $1 \%$ & $1 \%$ \\
\hline Hadley B2 2080 & $-14 \%$ & $10 \%$ & $7 \%$ & $3 \%$ & $-9 \%$ & $2 \%$ & $2 \%$ \\
\hline & \multicolumn{7}{|c|}{ Water Deficit } \\
\hline & Sacramento & Rhine & Syr Darya & Volta & $\begin{array}{l}\text { Zayandeh } \\
\text { Rud }\end{array}$ & Walawe & Mekong \\
\hline $\begin{array}{l}\text { MaxPlank } \\
2020\end{array}$ & $1 \%$ & $1 \%$ & $0 \%$ & $-5 \%$ & $2 \%$ & $-29 \%$ & $-24 \%$ \\
\hline $\begin{array}{ll}\text { MaxPlank } & \text { B2 } \\
2080 & \\
\end{array}$ & $3 \%$ & $1 \%$ & $1 \%$ & $-1 \%$ & $4 \%$ & $-29 \%$ & $-7 \%$ \\
\hline Hadley A1 2020 & $1 \%$ & $2 \%$ & $-5 \%$ & $0 \%$ & $1 \%$ & $-26 \%$ & $-32 \%$ \\
\hline Hadley A1 2080 & $4 \%$ & $4 \%$ & $6 \%$ & $2 \%$ & $5 \%$ & $18 \%$ & $-60 \%$ \\
\hline Hadley B2 2020 & $2 \%$ & $-2 \%$ & $-1 \%$ & $-5 \%$ & $2 \%$ & $-30 \%$ & $-23 \%$ \\
\hline \multirow[t]{3}{*}{ Hadley B2 2080} & $3 \%$ & $-3 \%$ & $-1 \%$ & $-1 \%$ & $4 \%$ & $-30 \%$ & $-5 \%$ \\
\hline & \multicolumn{7}{|c|}{ Water Available } \\
\hline & Sacramento & Rhine & Syr Darya & Volta & $\begin{array}{l}\text { Zayandeh } \\
\text { Rud }\end{array}$ & Walawe & Mekong \\
\hline $\begin{array}{l}\text { MaxPlank } \\
2020\end{array}$ & $0 \%$ & $-1 \%$ & $-1 \%$ & $-3 \%$ & $6 \%$ & $-29 \%$ & $-25 \%$ \\
\hline $\begin{array}{l}\text { MaxPlank } \\
2080\end{array}$ & $1 \%$ & $-6 \%$ & $-3 \%$ & $5 \%$ & $9 \%$ & $-29 \%$ & $-7 \%$ \\
\hline Hadley A1 2020 & $1 \%$ & $-1 \%$ & $-5 \%$ & $2 \%$ & $2 \%$ & $-26 \%$ & $-32 \%$ \\
\hline Hadley A1 2080 & $1 \%$ & $-9 \%$ & $-1 \%$ & $11 \%$ & $12 \%$ & $18 \%$ & $-61 \%$ \\
\hline Hadley B2 2020 & $1 \%$ & $-3 \%$ & $-2 \%$ & $-3 \%$ & $4 \%$ & $-30 \%$ & $-24 \%$ \\
\hline Hadley B2 2080 & $1 \%$ & $-8 \%$ & $-4 \%$ & $5 \%$ & $6 \%$ & $-30 \%$ & $-5 \%$ \\
\hline
\end{tabular}

*NOTE: Values are relative to base values

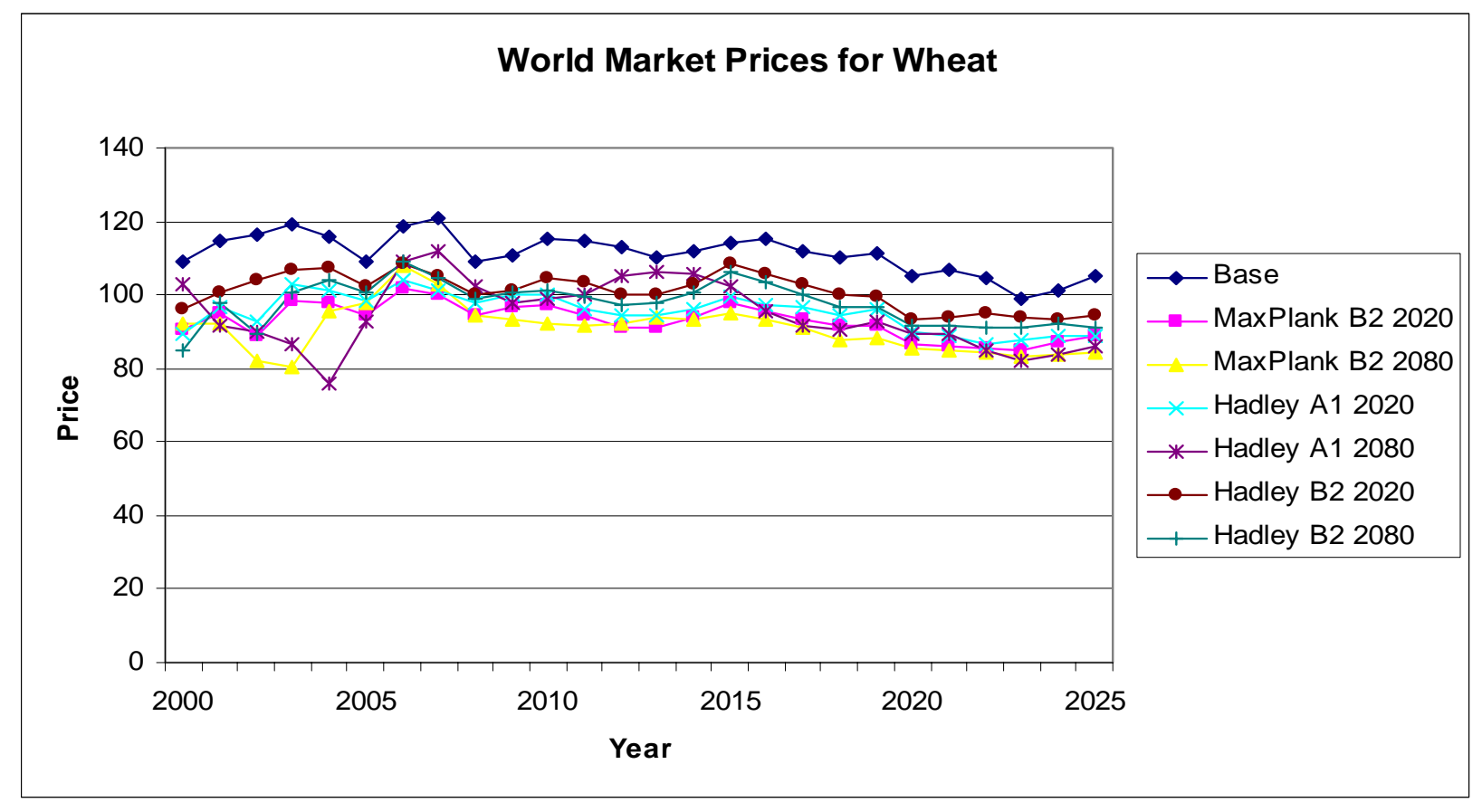

Figure 3.9 World Market Prices for Wheat 


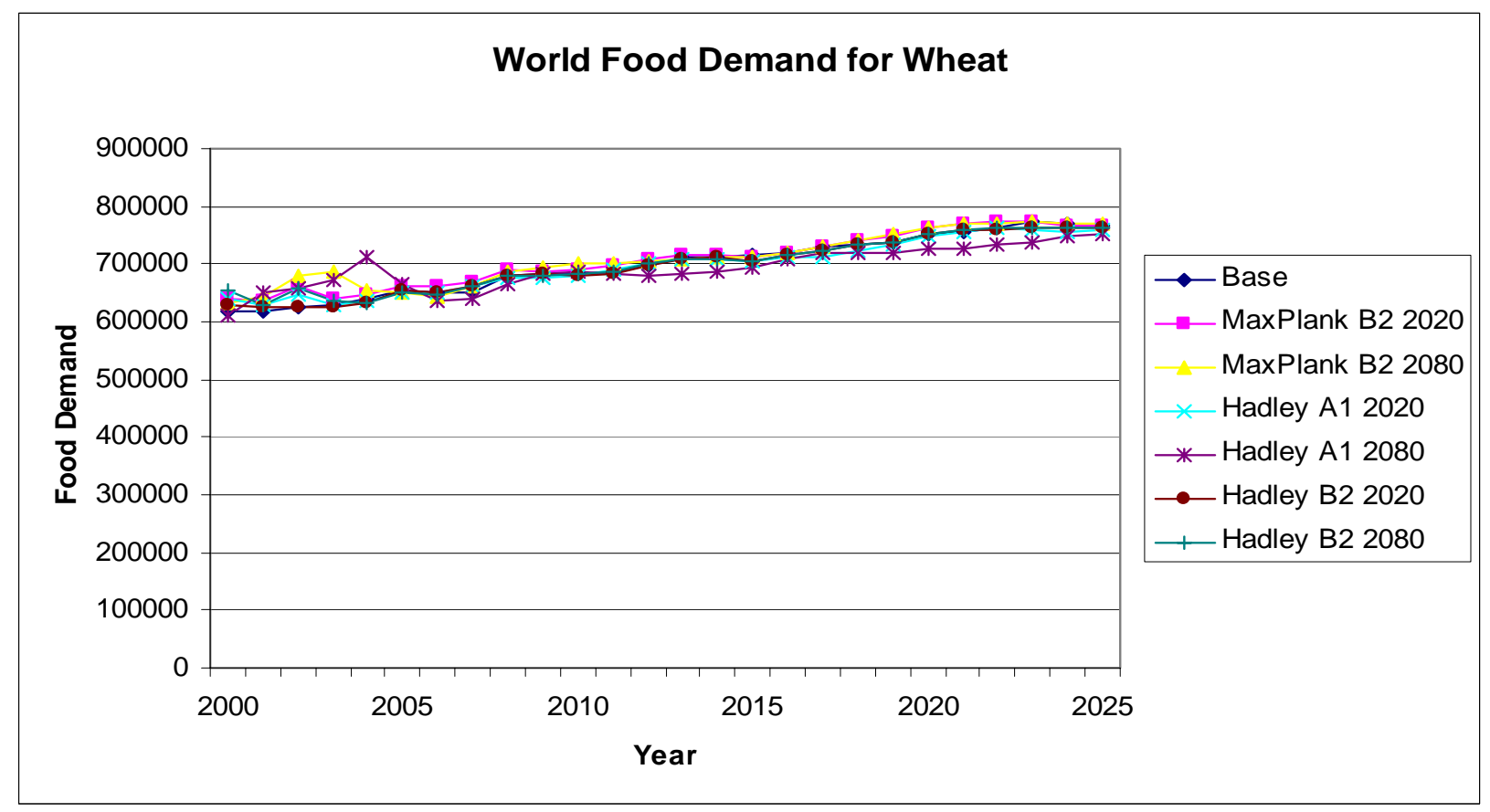

Figure 3.10 World Food Demand for Wheat

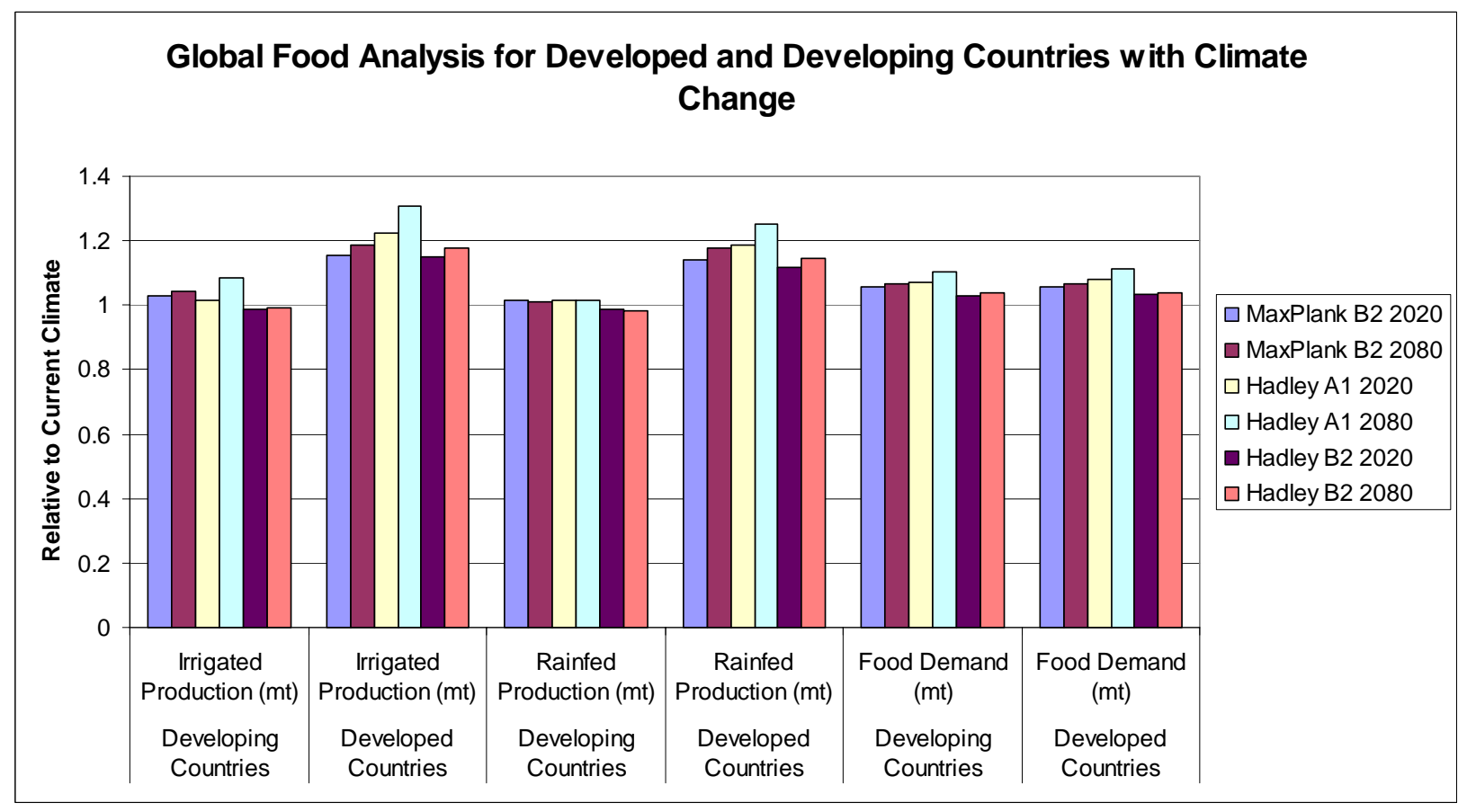

Figure 3.11 Global Food Analysis for Developed and Developing Countries with Climate Change

Figure 3.12 shows total production increasing slightly for rice, increasing more for maize, and slightly increasing and decreasing for wheat depending on the climate scenario. 
These same trends are seen in both irrigated and rainfed production with the exception that irrigated wheat production decreases and rainfed wheat production increases.

The increase in global production results in a decrease in world market prices (Figure 3.13.) Rice shows an approximately $20 \%$ decrease, wheat between 10 to $20 \%$ while maize experiences 40 to $50 \%$ price drops. These price changes correlate somewhat directly to the production changes but changes in the other crops and consumer preference can also impact prices and market conditions.

Figure 3.14 shows the results of decreased prices, that is increased food demand and decreased hunger. Even in primarily subsistence agricultural economies, world and local prices impact subsistence household food consumption. Thus decrease in prices will lead to increased demand in all income sectors and should be reflected in reduced population at risk of hunger.

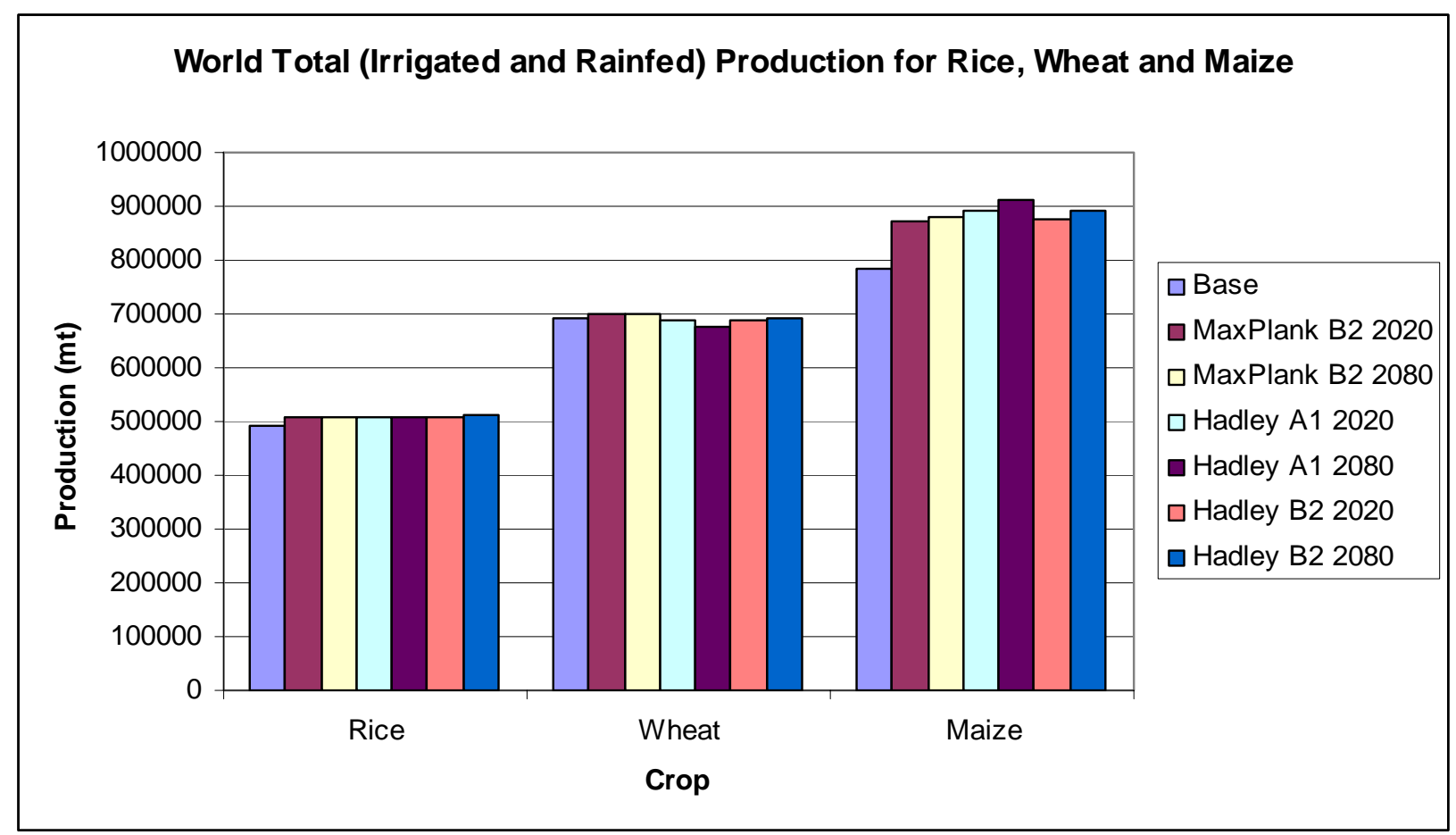

Figure 3.12 World Total (Irrigated and Rain fed) Production for Rice, Wheat and Maize 


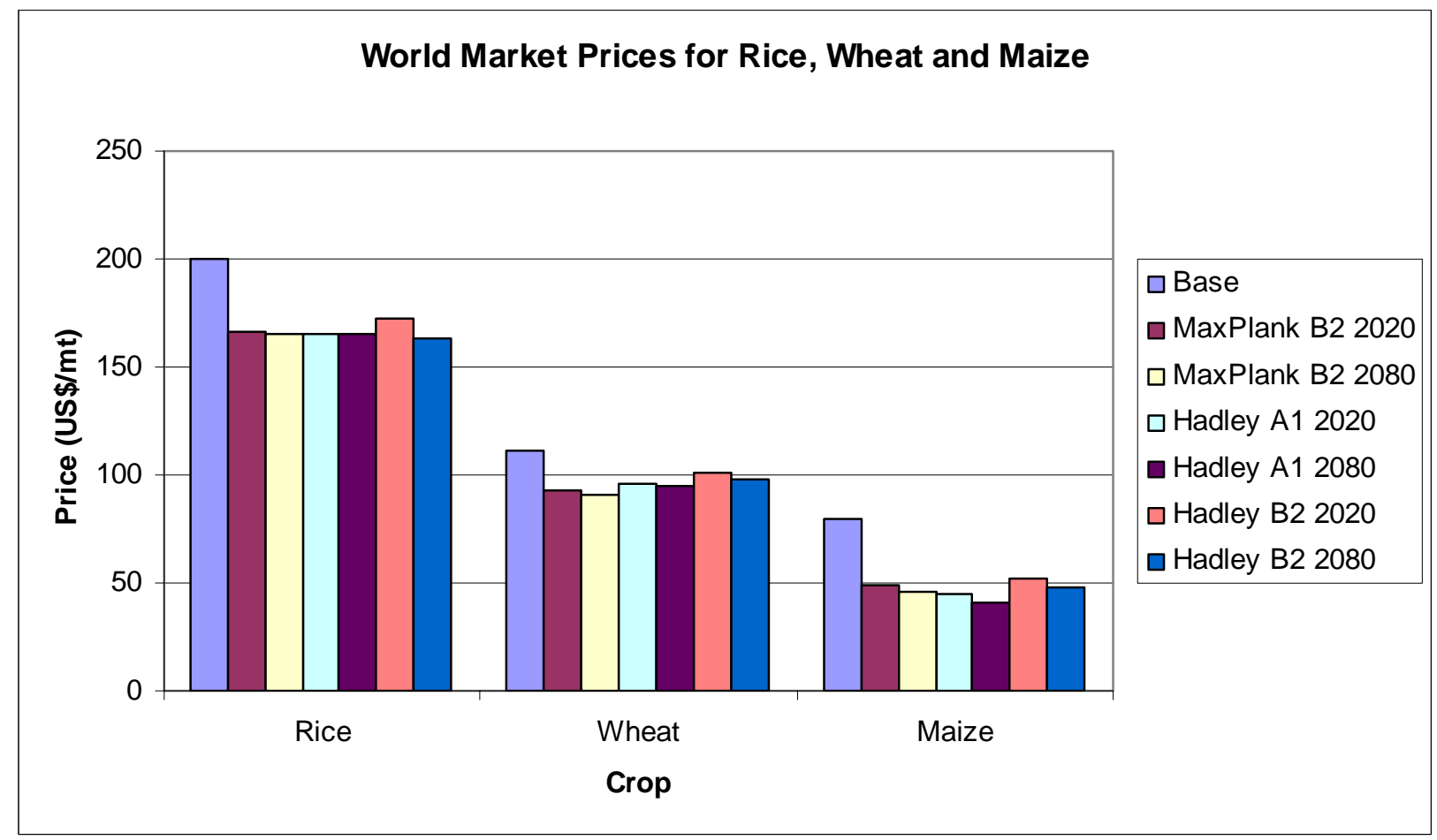

Figure 3.13 World Market Prices for Rice, Wheat and Maize

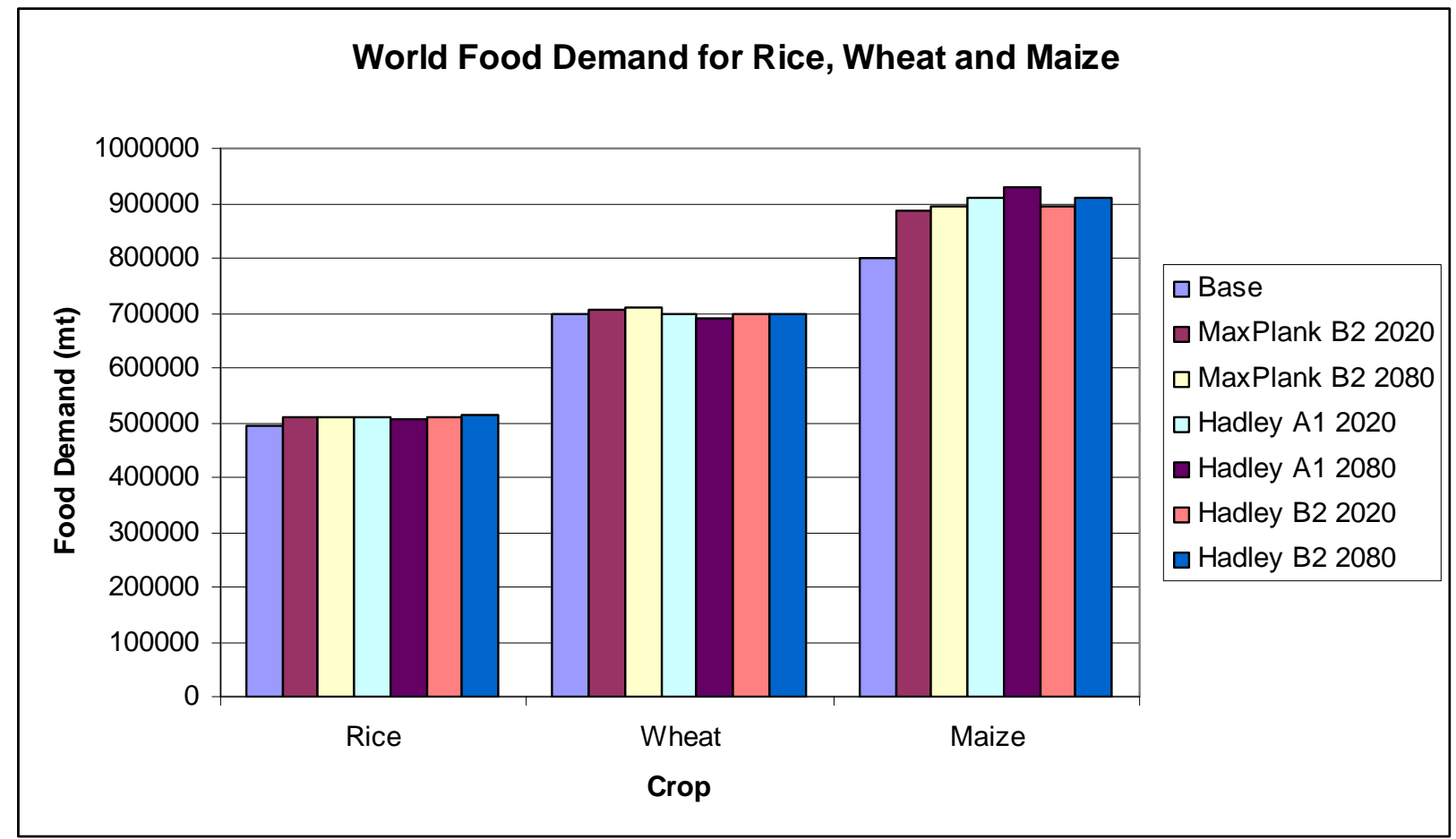

Figure 3.14 World Food Demand for Rice, Wheat and Maize 


\section{Climate Variability}

GCM based climate scenarios provide only a single estimate of a future climate. Whether that realization is used directly or as a relative change to a historic climate period, the output reflects only the mean monthly changes. To test how sensitive our agricultural system is to variability we used a Monte Carlo approach and simulated many realizations of future climates known as an ensemble of climates. With these climate ensembles we are able to examine how changes in climate variability as opposed to greenhouse gas mean changes impact food production, prices and demand. Two climate variability scenarios each with an ensemble of 30 future climates were developed and run through the IMPACT-WATER Model and results are presented below.

Figure 3.15 shows the impact of increased and decreased ENSO events on global food demand. While halving ENSO event frequency has little effect, doubling ENSO events has appreciable effects. Food demand decreases because yield and production decrease and prices increase on average because of the impacts of more frequent flood and drought extreme events. Lack of water from droughts decreases production, while increased water from flooding cannot be fully utilized. So even though mean water availability remains the same, the mean food production goes down.

Figures 3.16 and 3.17 show the impact of the variability scenarios on a range of model variables disaggregated by developing and developed regions. The results show that developing regions are impacted more than developed because developing countries are located in more highly variable climate regions and generally have lower firm yields from reservoir storage to absorb the extreme events.

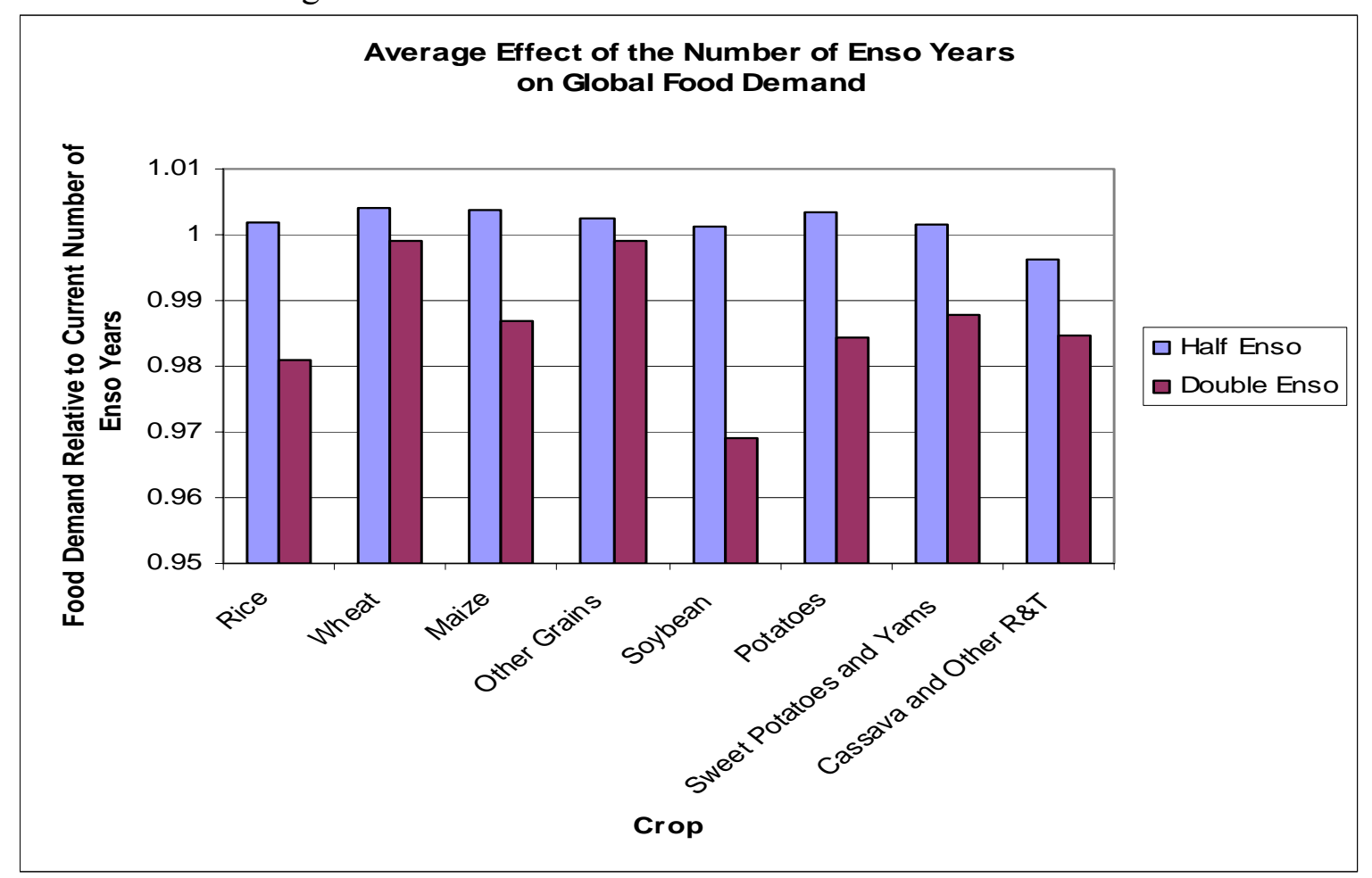

Figure 3.15 Average Effect of ENSO Years on Global Food Demand for Major Crops 


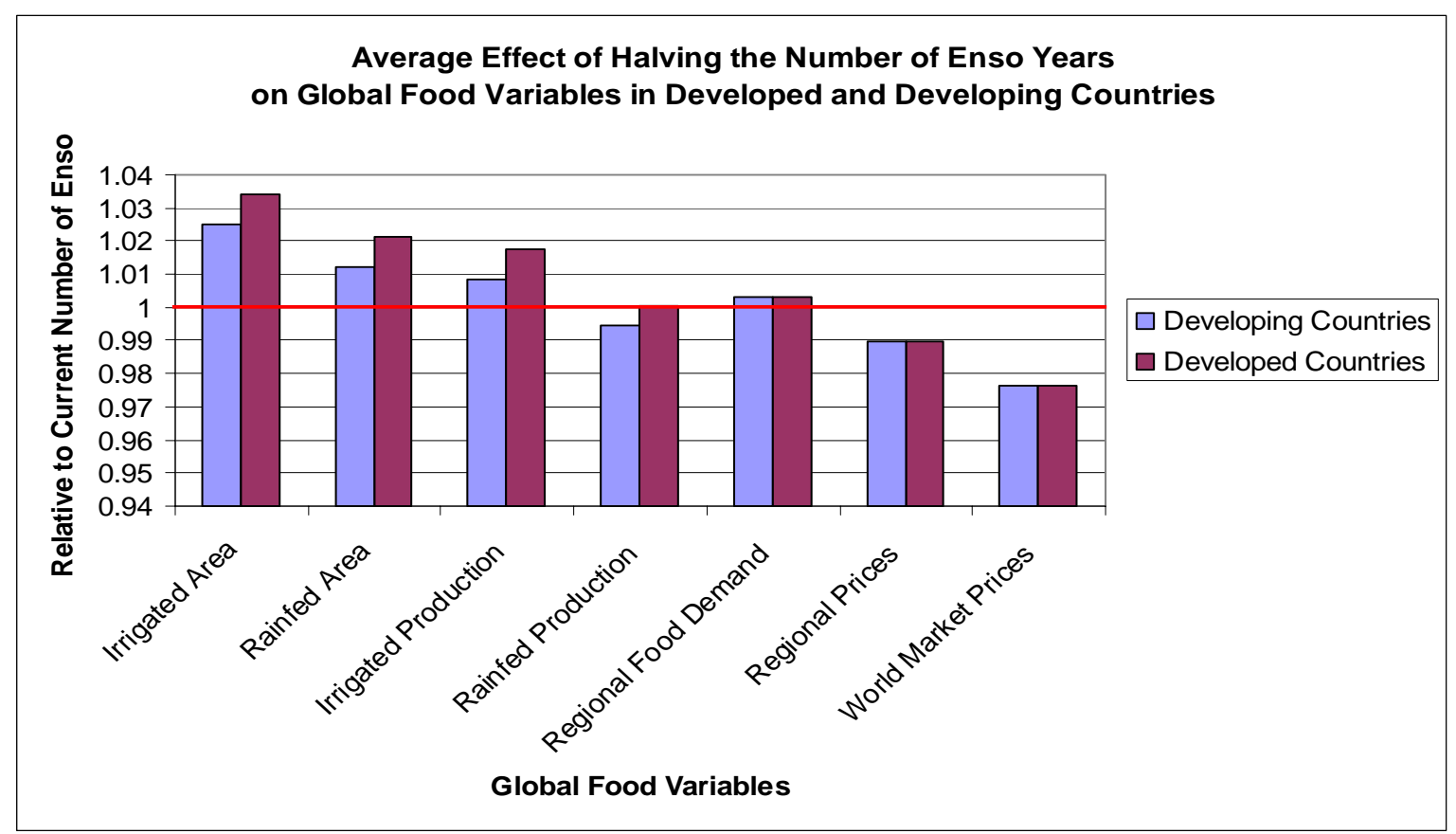

Figure 3.16 Global Effects of Halving ENSOs

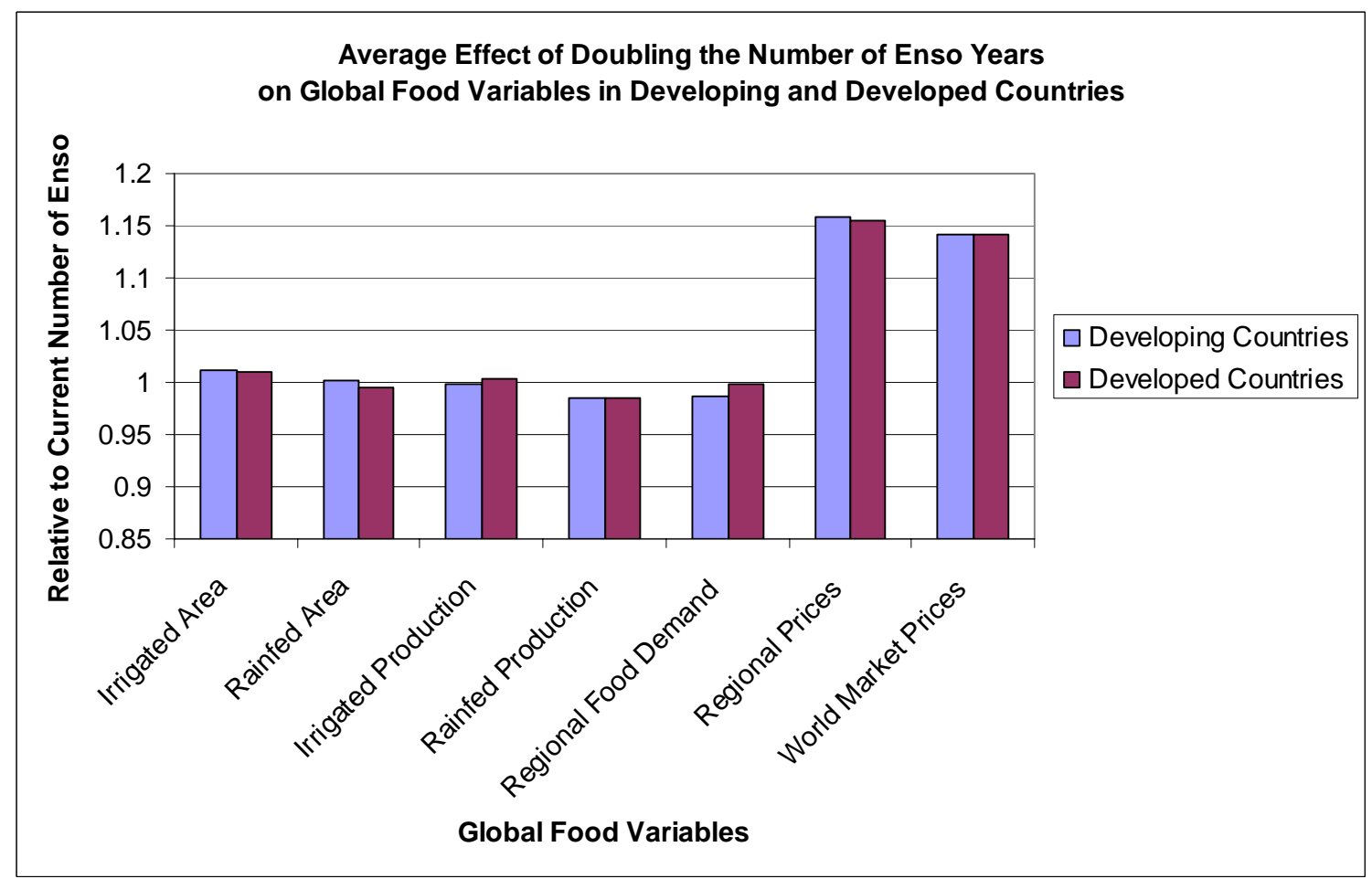

Figure 3.17 Global Effects of Doubling ENSOs

Climate Change versus Climate Variability 
A question often posed is what is the relative importance of change in mean versus changes in the variability of climate variables on food systems? Since this assessment examined both type of scenarios we are able to present some comparative results.

Figure 3.18 shows the relative impact on global food demand and Figure 3.19 on food prices for climate change versus climate variability. The results show that for food demand the climate change scenarios have a positive affect while the variability scenarios have none or a negative affect. This is due to the fact that under increased greenhouse gases there will be a $\mathrm{CO} 2$ fertilization impact on certain crops. Globally, this effect dominates any negative impact of temperature increases or precipitation decrease. Under the variablity scenarios, lack of water from droughts decreases production and increased water from flooding can not be fully utilized. Thus even though the mean water availability remains the same, the mean food production goes down with no fertilization effects. This leads to higher prices and lower demand and increased risk of hunger.

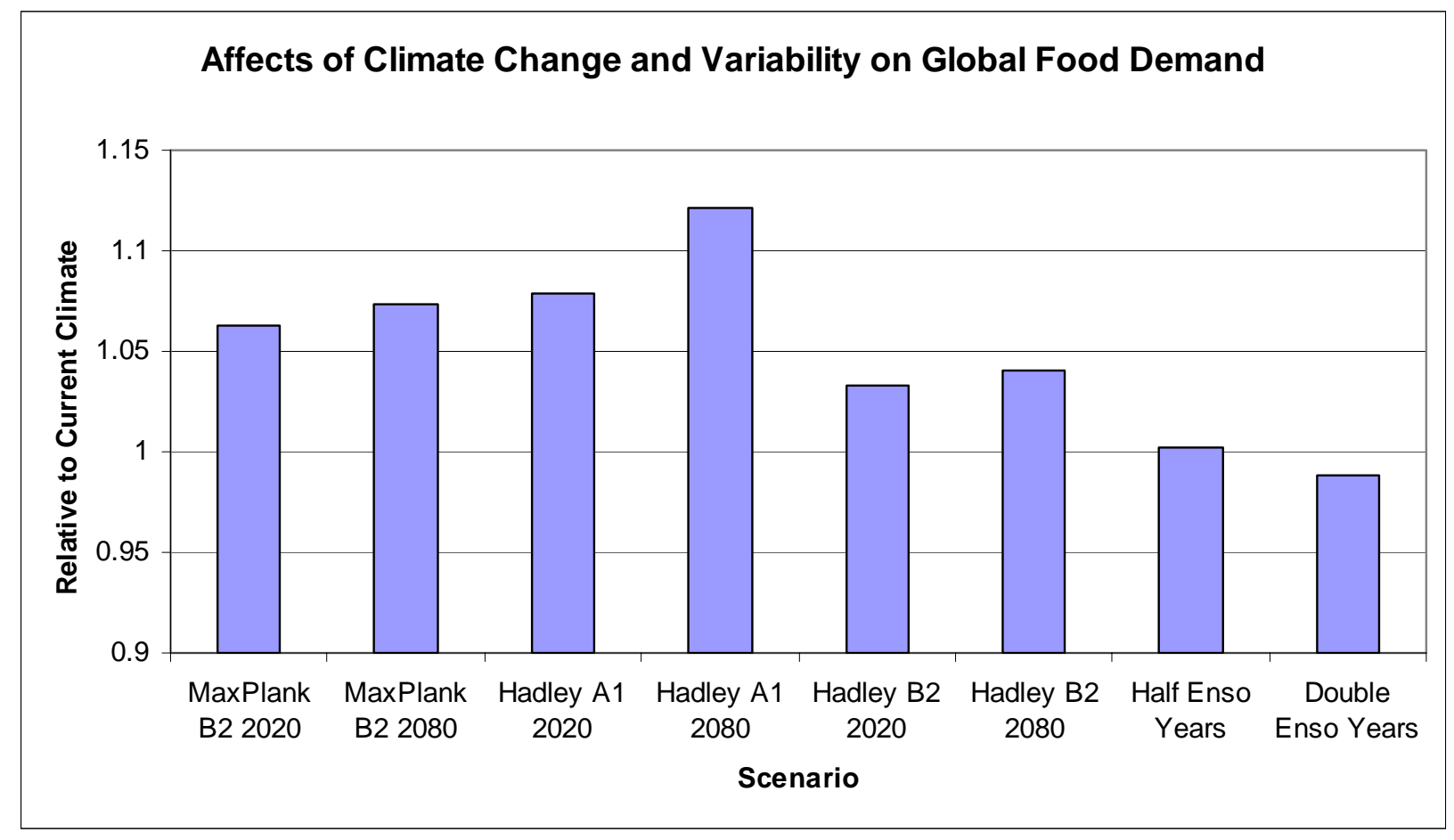

Figure 3.18 Effects of Climate Change and Variability on Global Food Demand 


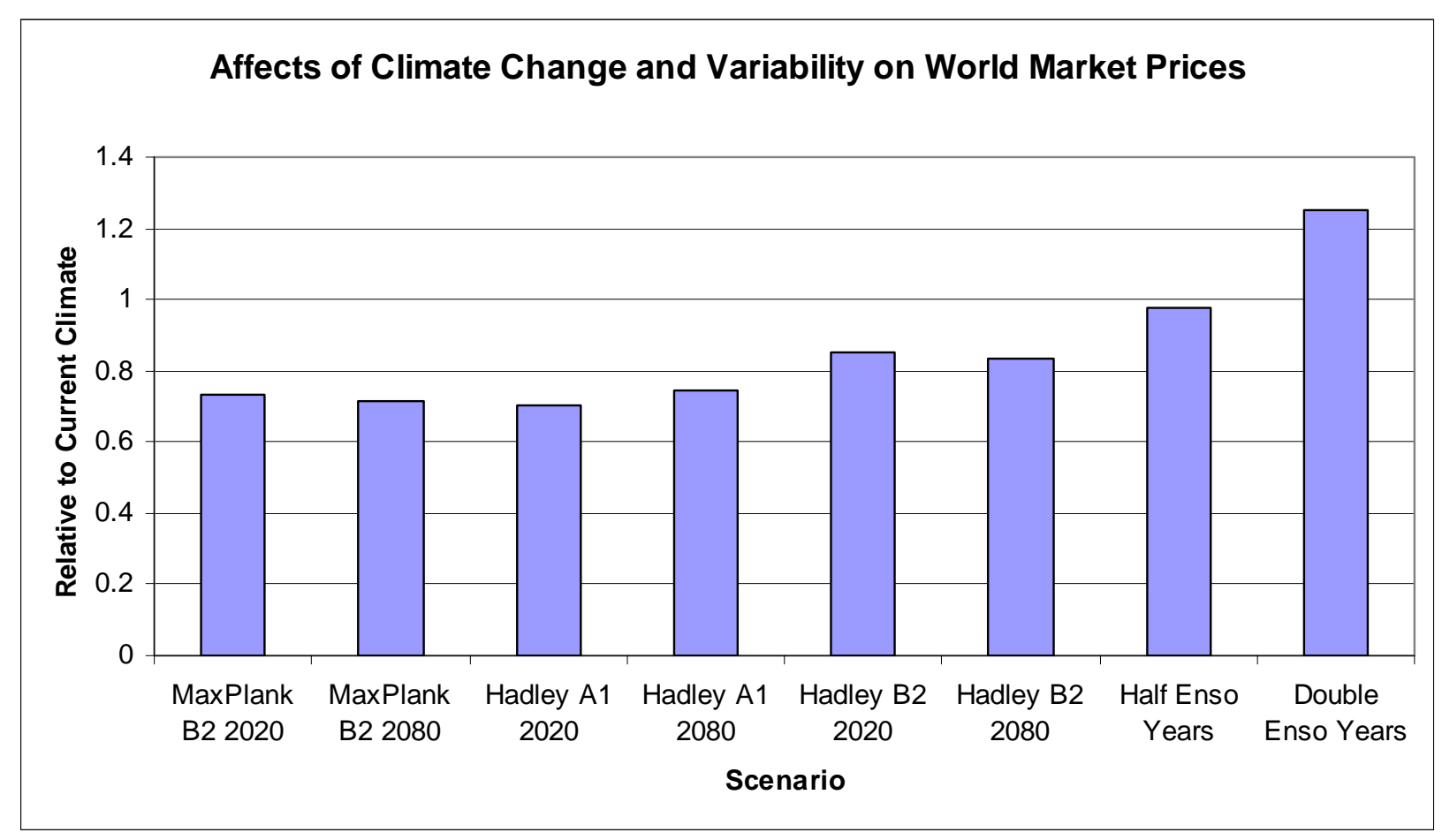

Figure 3.19 Effects of Climate Change and Variability on World Market Prices

\section{Conclusions}

This analysis was the result of a heroic effort of many scientists learning the language and data needs of each other. The output was extensive and is summarized in the sections above and presented in detail in supplemental reports. While there were many insights from the work, we have settled on 8 major conclusions.

1. Geographic Scale Matters: The scale of analysis has a major impact on the sign and magnitude of climate change assessments.

2. Mitigating and Accentuating: In integrated systems, climate impacts across the sectors can either mitigate or accentuate climate change impacts when assessed in an integrative manner. For example, results from the GAEZ model show nonwater stress crop yield decreasing due to temperature effects, but after evaluating results from the IMPACT models, increased irrigation or effective precipitation in some cases lead to increased production in these river basins.

3. Prices are important for food demand: Price is a very important factor when assessing climate change impacts on food demand and nutritional status.

4. Climate Change versus Climate Variability: For the scenarios examined, climate change has much more positive impact as compared to climate variability on food demand with prices increasing with increased climate variability.

5. Developing versus Developed Countries: In all scenarios, the developing country regions were impacted more severely than the developed regions.

6. Irrigated versus Rainfed: Rainfed production can be impacted much more than irrigated production because there is not the possibility to supplement water deficits with irrigation. Under some wetter GCM scenarios rainfed yield may 
increase dramatically due to increases in effective precipitation. There is no generalization that can be made.

7. Technological Change Importance: Dynamic assessments of climate change must take into account socio-economic changes, particularly yield growth in agricultural assessments. Even though production over the 30 year simulation period may be negatively impacted by climate, yields are continuing to increase and per capita food demand is greater in 2025 than 1995 for all climate change scenarios examined.

8. Global versus Local Models: Both are needed. Global markets and trade greatly effect prices and food demand and must be modeled. Local scale models capture local conditions at the most appropriate scale.

\section{0 Relative Impacts of Hydrologic and Climate Impacts on Crops}

IMPACT with water was run by keeping the hydrology at the 1961 to 1990 baseline but imposing the climate change scenario impacts on crops yields forecast to 2025 with technological based increased yields (referred to as No Hydrology). This was compared to running IMPACT with the climate change impacts on hydrology as modeled by WATBAL and keeping the crop yield at 1995 base levels (Referred to as No Yields). These runs were then compared to the runs with full climate change impacts on both hydrology and crop yields. The results are Figures 4.1 to 4.8 show that in all cases the consideration of the impacts of climate change on hydrology are more important to the results than including the impacts of climate change on yields. 


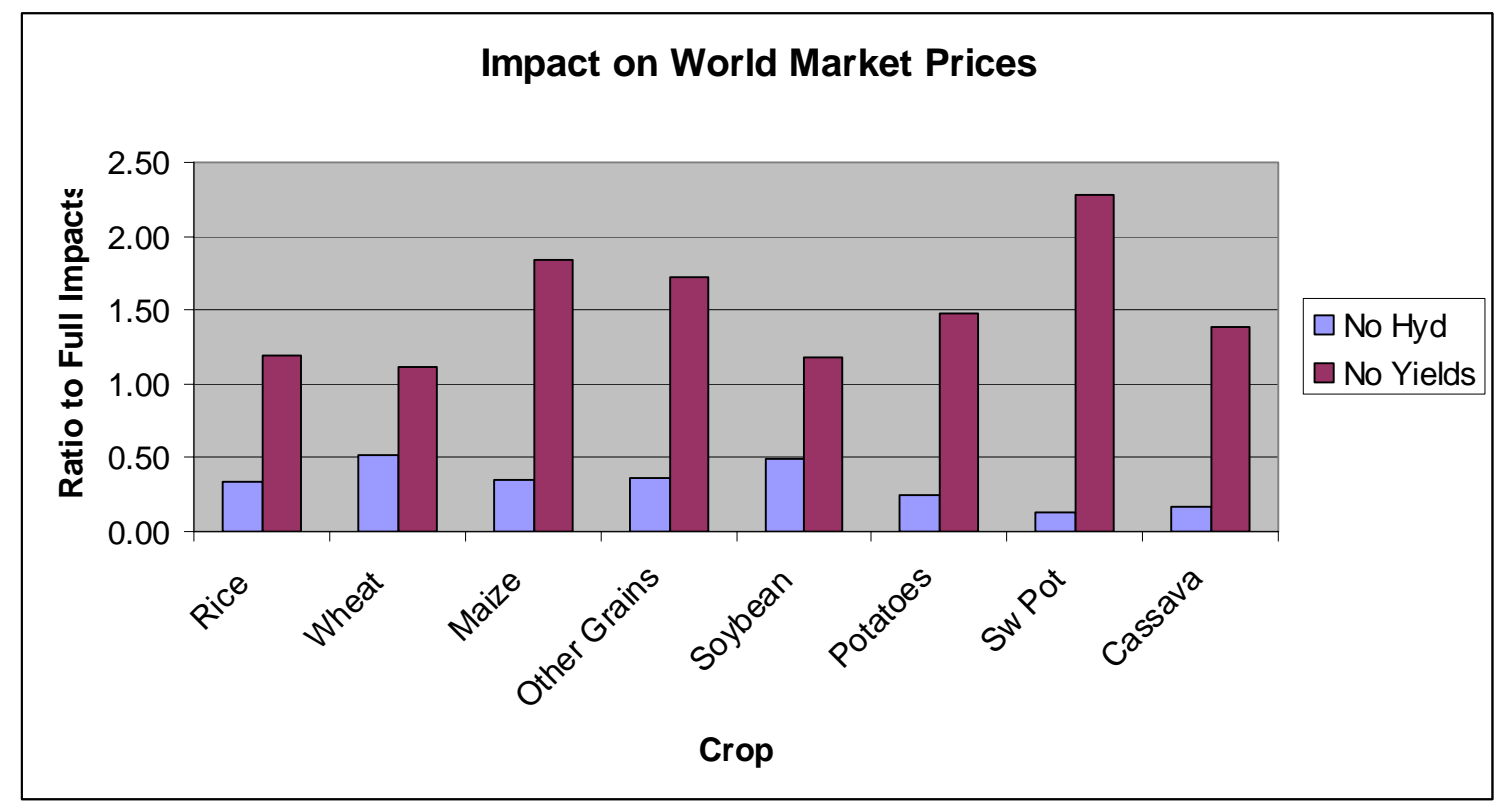

Figure 4.1

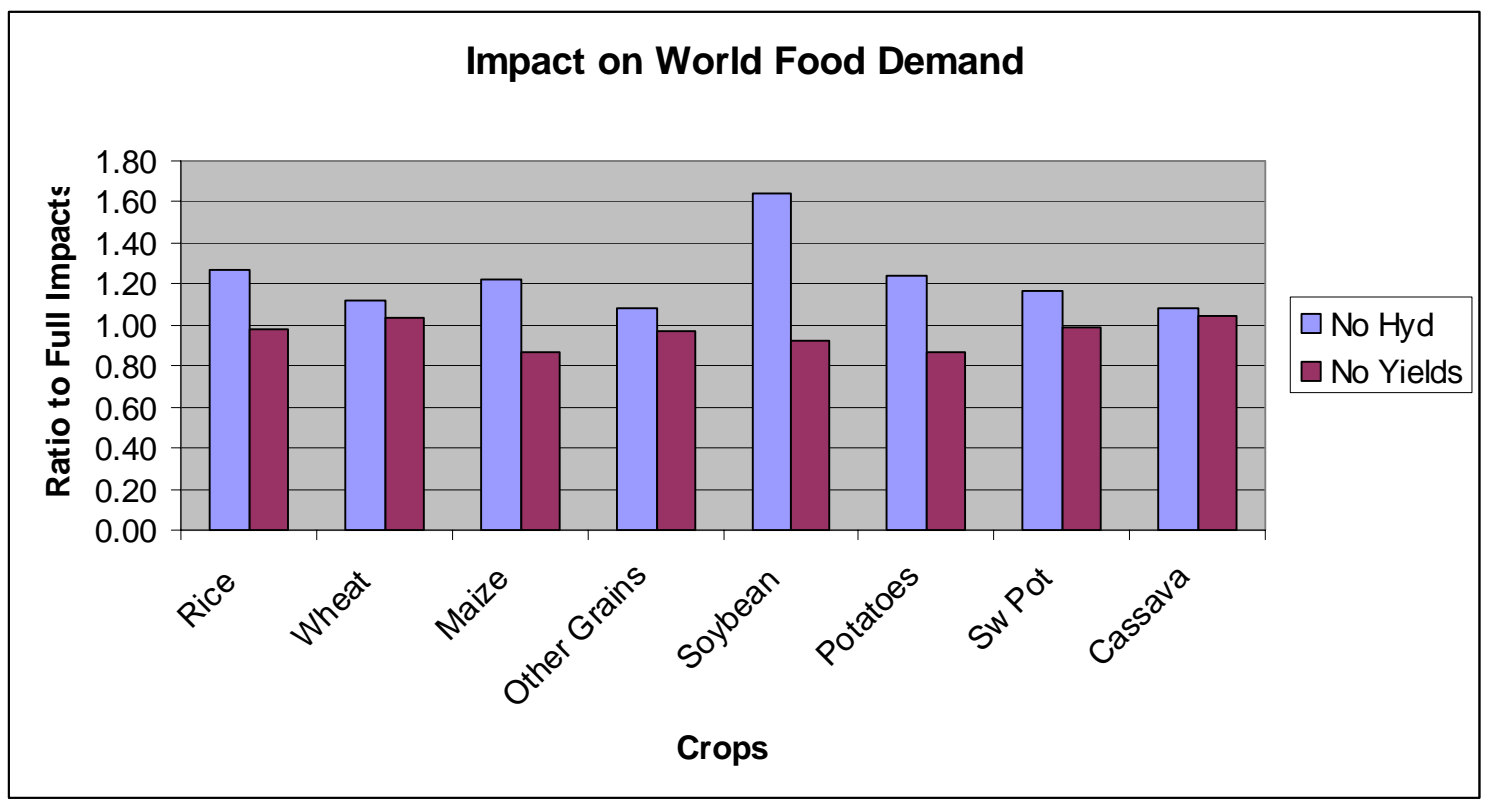

Figure 4.2 


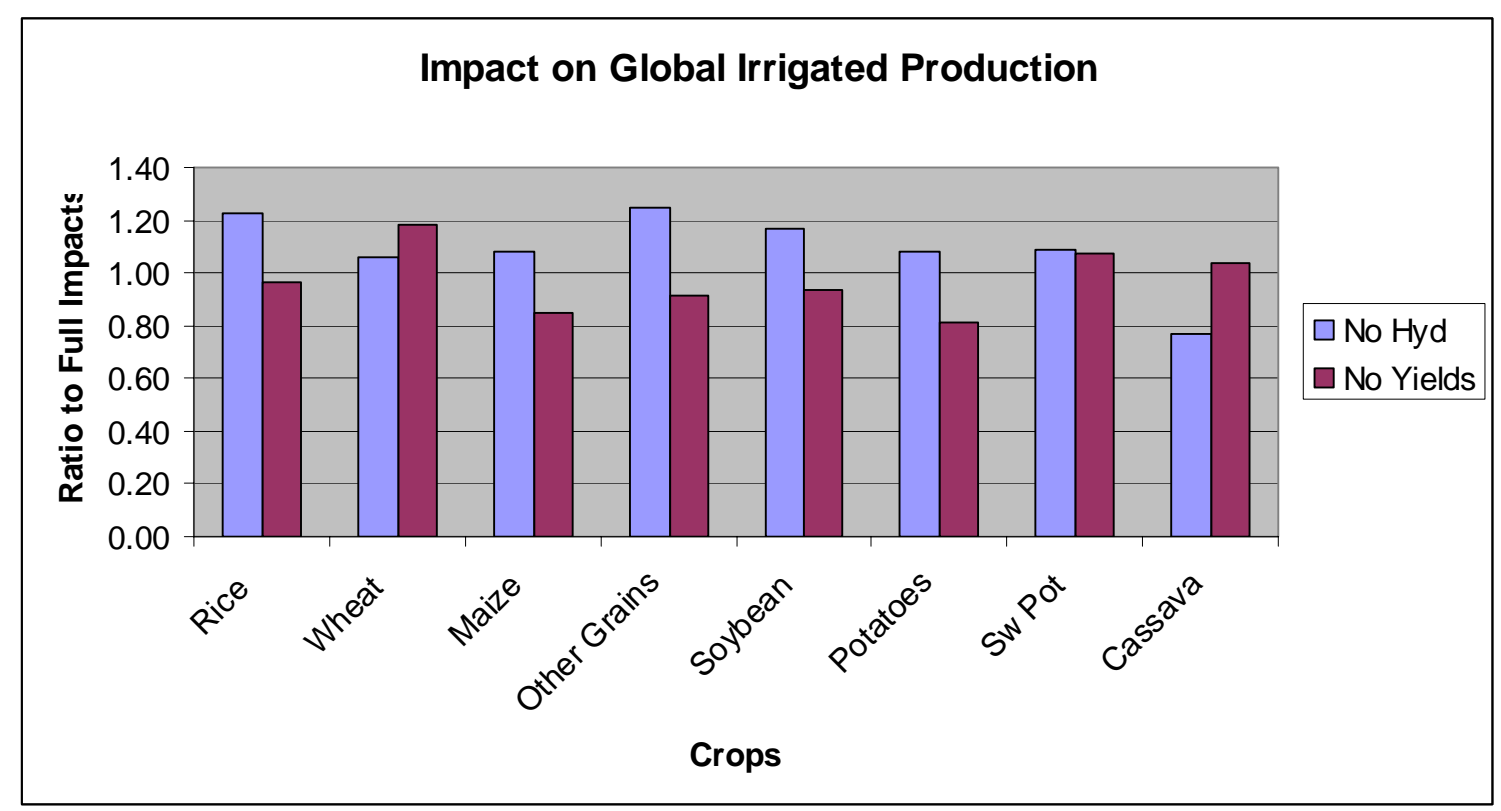

Figure 4.3

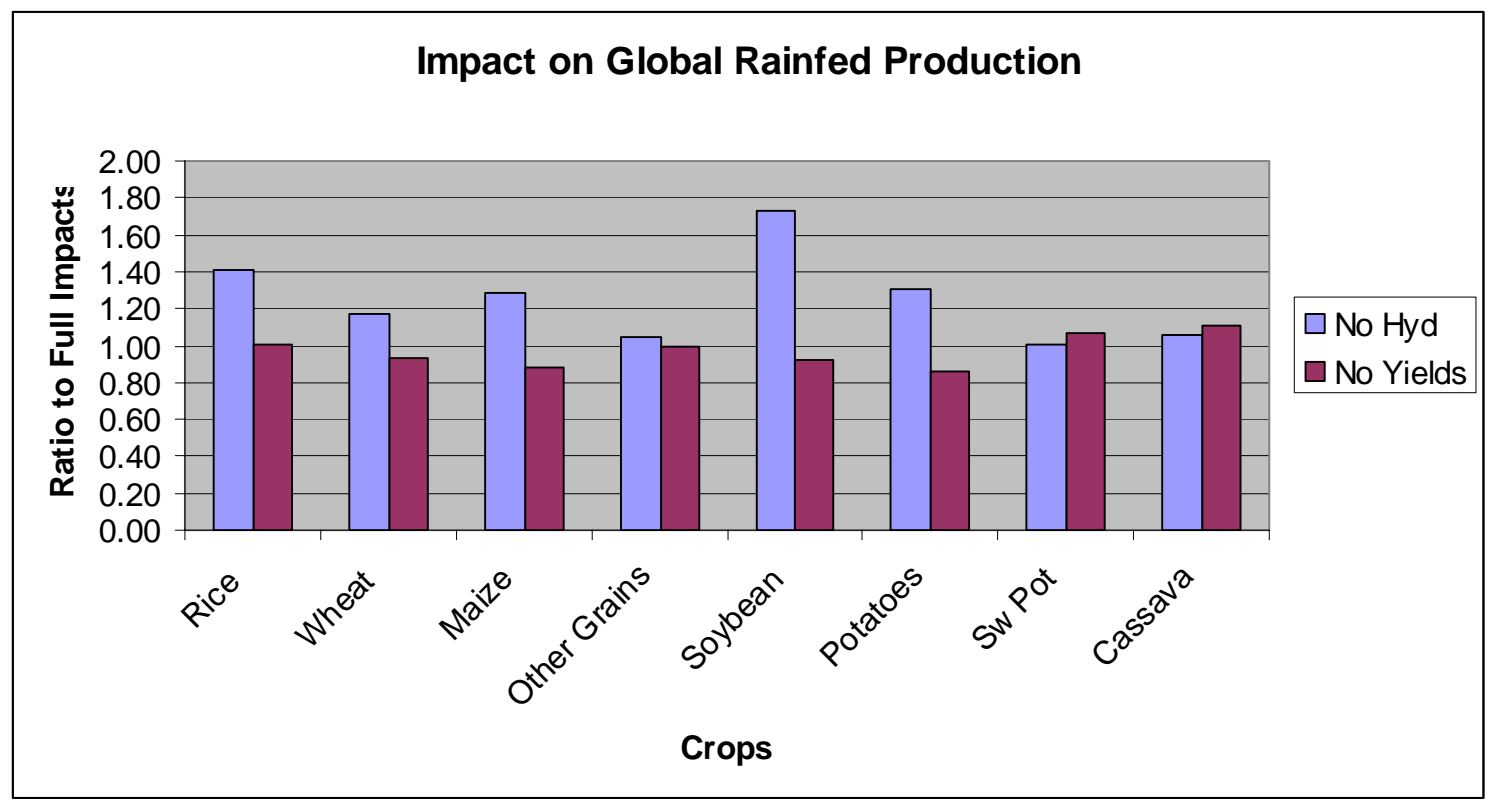

Figure 4.4 


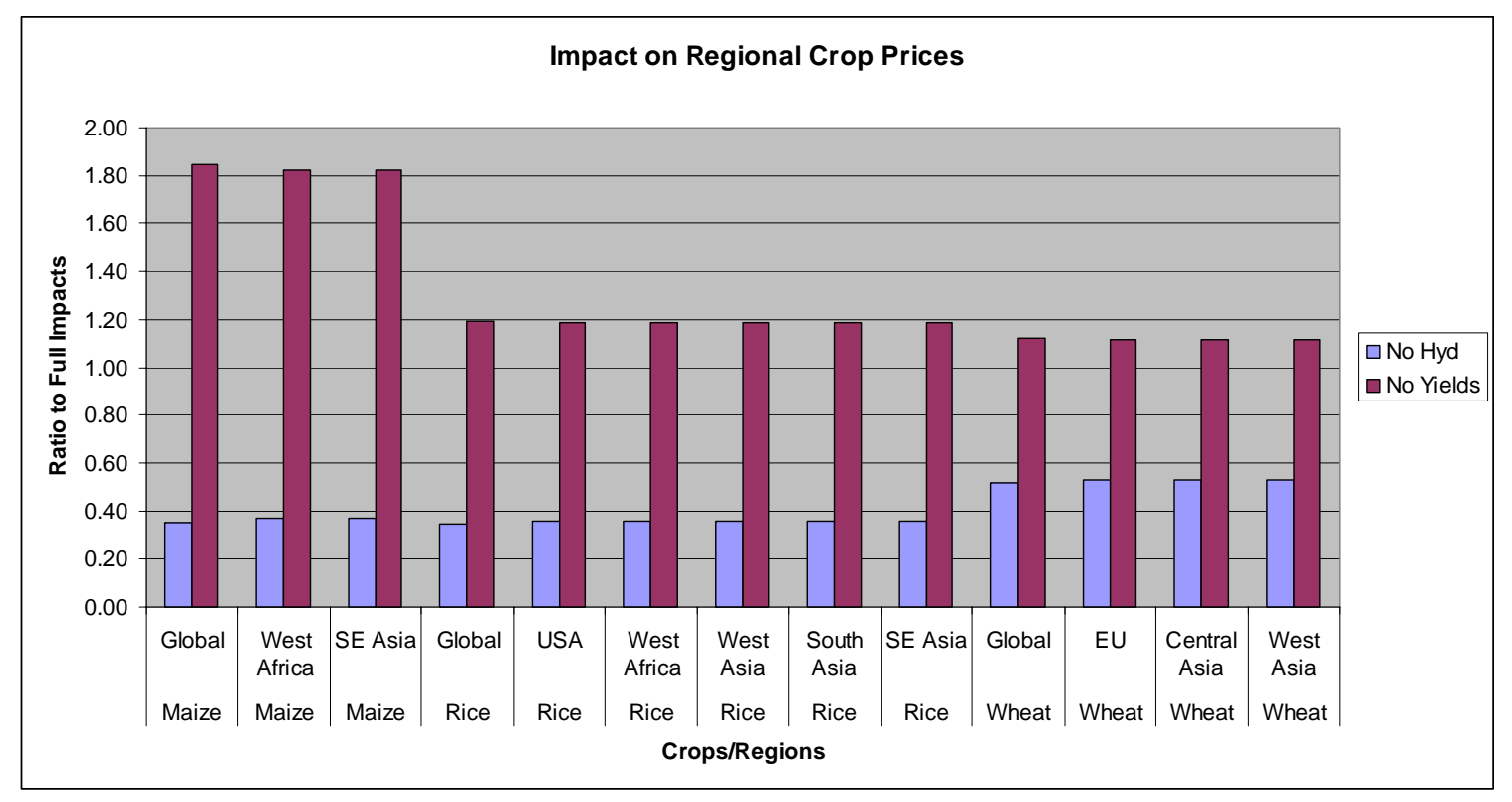

Figure 4.5

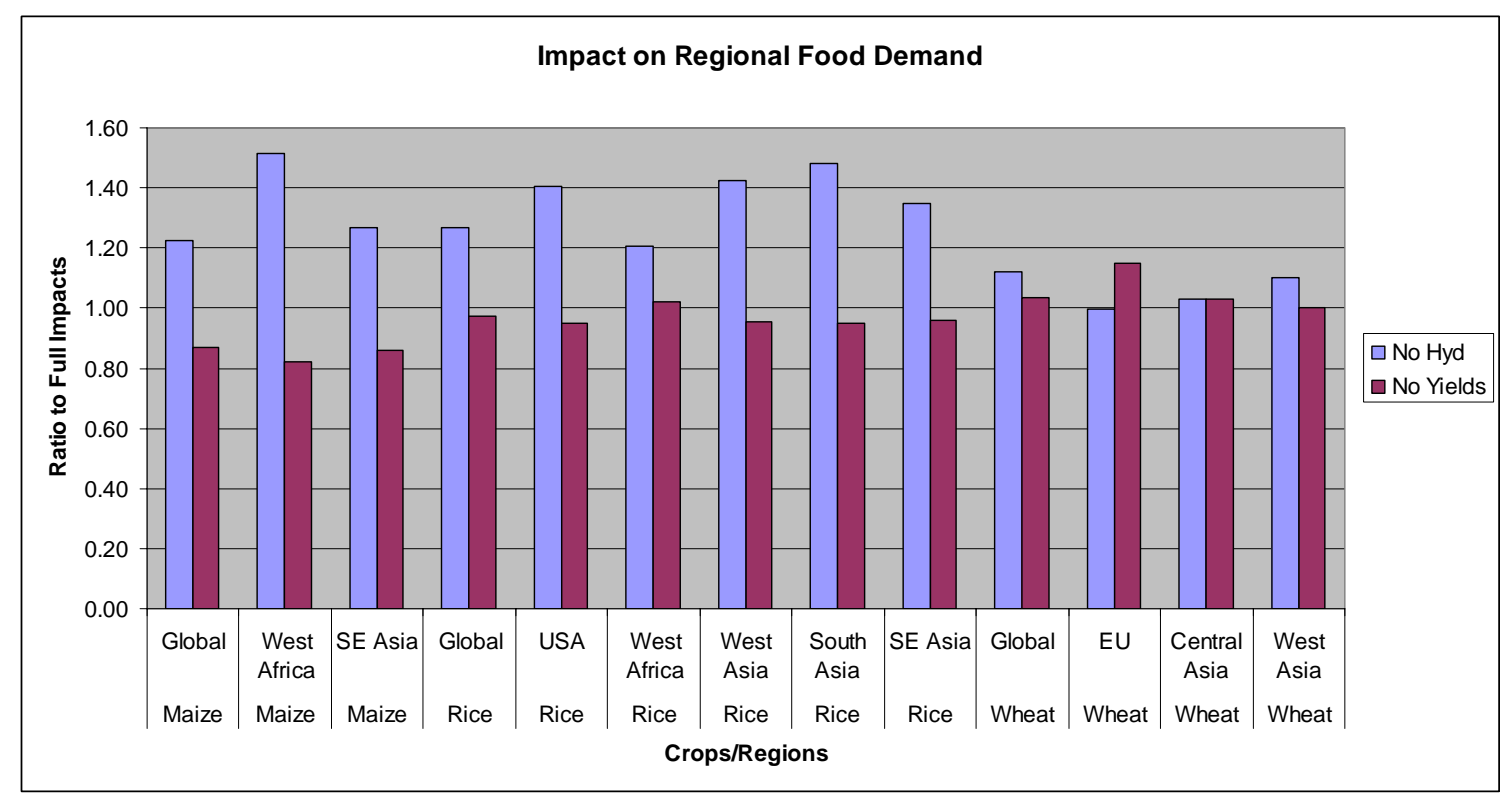




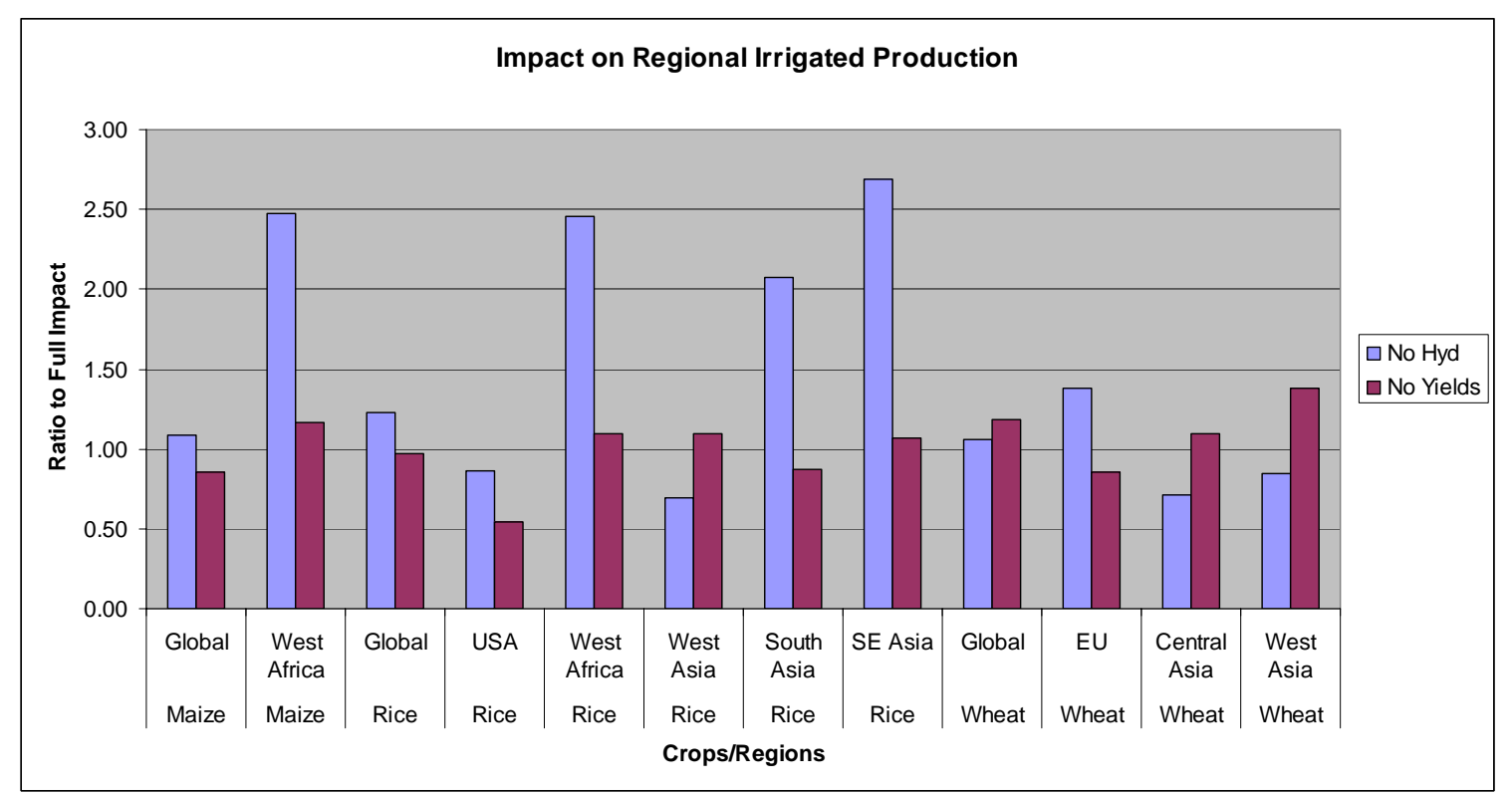

Figure 4.7

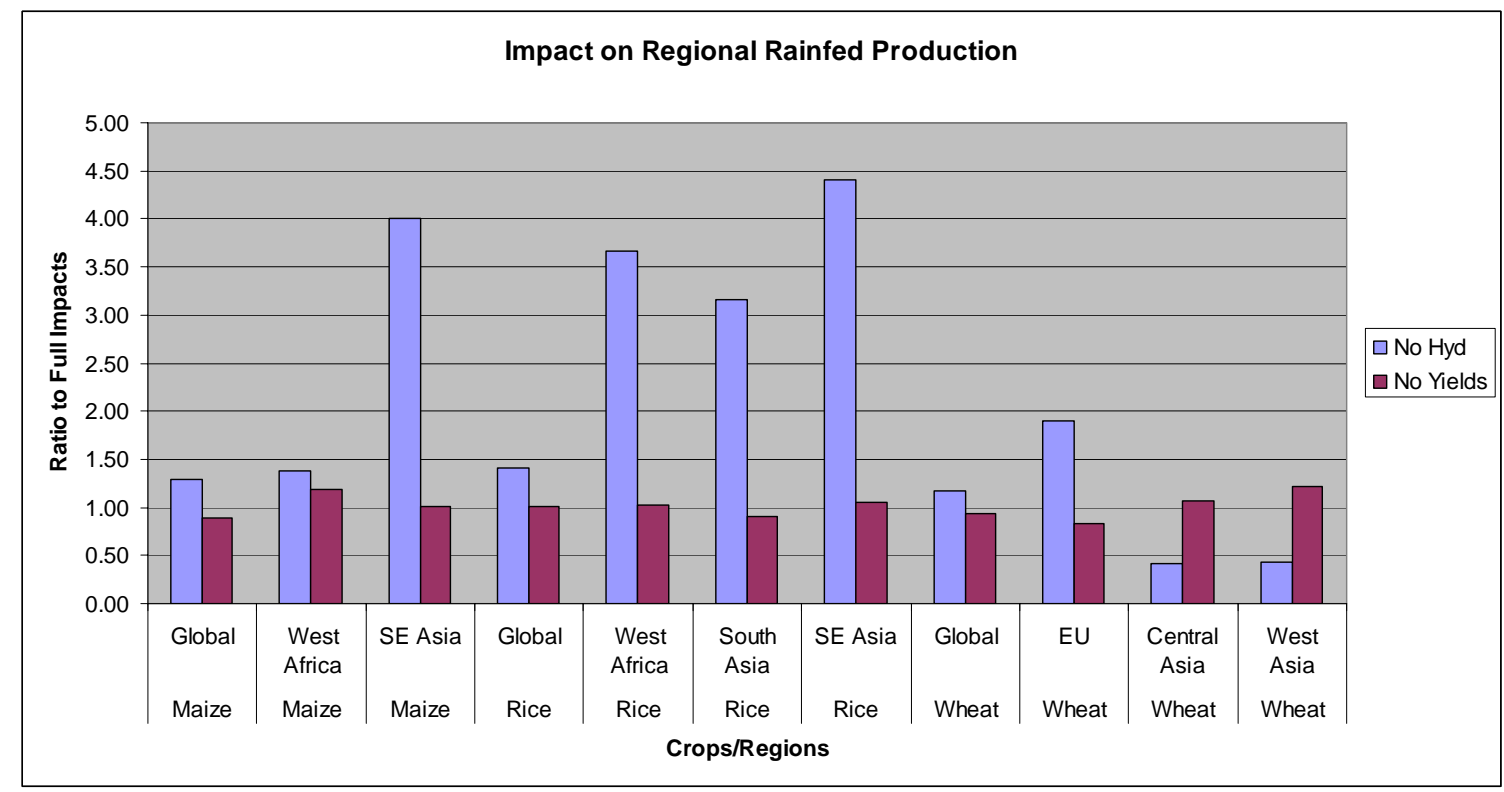

Figure 4.8

\subsection{Explicit Consideration of Consumption, Groundwater, and InstreamFlow Needs: A Case Study of China}

Using China as a case study because it represents a range of hydrologic, data, and socioeconomic conditions, the following concepts in aggregated water resources modeling were explored: using net water available for consumption as the key variable instead of water available for withdrawal; estimating demands as consumptive needs, not total need; using a water balance model based upon river basins instead of grids; and modeling the 
explicit hydrologic and cost interactions of ground and surface waters. The advantage of comparing water available for consumption (that is, after instream needs have been met) and consumptive demands of water users is that they can be directly compared. A more traditional method of comparing total water availability to total demands is oftentimes misleading because this method does not consider the re-use of water downstream as it is withdrawn by a user and the partially consumed water returned to the system. The difficulties of using water available for consumption and consumptive demands is that it requires considerable pre-modeling processing of data. Therefore a better alternative is to include in one model the total supply available, the instream flow requirements, total water demands, and their return flows after consumption.

Water availability in this case study was based upon fitting a water balance model to entire river basins. While this is computationally easier than modeling by grids as in the water data preparation for IMPACT, the drawbacks of modeling by river basin are that there is no accounting for the spatial distribution of precipitation, land use, topography, geology, and climate changes. The computational difficulties are also becoming less each year due to computer hardware and software advances.

A water balance model produces an estimate of the streamflow at a location. In many cases, the streamflow is the sum of water entering the river from groundwater and of water entering from surface or just-below-surface processes. Thus the reliability of streamflow at this site is result of the reliabilities of the groundwater and surface water systems and groundwater withdrawals thus influence the reliability of streamflow at this site. Therefore groundwater withdrawals and return flows must be modeled to estimate the impacts of water use on streamflows. In cases where groundwaters directly contribute to surface waters, groundwater withdrawals and return flows can be subtracted from and added back to surface flows. Similarly, while obvious, the costs of developing groundwaters and surface waters are different and thus influence the costs of water supply. In aggregated modeling, we have used estimates of the relative uses of groundwater and surface water at locations to develop a combined cost of water supply for a region.

\subsection{Developing Reservoir Cost Curves for the Nine Major Watershed Regions in China}

A methodology is presented upon the past work of Löf and Hardison (1966) and Wollman and Bonem (1971) to use basin topography to estimate reservoir storage costs. Since the cost of storage varies by local physiography and the size of the reservoir, Löf and Hardison developed storage cost curves for eleven size classes and ten physiographic zones in the United States. The cost curves were then modified by Wollman and Bonem by normalizing the average unit cost over all physiographic zones and class sizes. Thus by assuming that the relationship between physiographic zone, size, and relative unit storage cost remains the same in each country, the cost of any size reservoir can be estimated using information on the topography in the region. In more detail, the average unit storage cost for the region of interest is obtained. A digital elevation model is then used to calculate the average slope of the regional topography, which is then correlated 
with the physiographic zones provided. The third step is multiply the regional normalized unit cost by the average unit cost in the region. The technique was validated for the cost of Three Gorges dam in China.

\subsection{Modeling of Surface Areas of Aggregated Reservoirs for Estimating Evaporation Losses}

Annual evaporation from reservoir storage is a substantial source of water loss in developed watersheds, particularly in arid regions. In some watersheds, such as the Nile, as much as $13 \%$ of the total available annual water can be lost due to evaporation from reservoirs. Therefore evaporation must be considered when assessing the usable water in a watershed. In order to calculate evaporation from storage, the relationship between storage surface area and storage volume must be estimated. This research analyzed the area-storage relationship at different scales in order to provide methods for estimating the area-volume relationship for individual reservoirs, multiple reservoirs, and entire watersheds when precise data on elevation, area, and volume for the reservoirs are not available.

For individual reservoirs, a pyramid approximation was found to provide an excellent estimate of the area-volume curve for individual reservoirs. In this method, the area is related to the volume as in Equation 1. C4 can be estimated from one known point on a reservoir storage volume area curve (usually corresponding to normal or maximum storage) in Equation 2.

$$
\begin{aligned}
& A=3 \cdot \sqrt[3]{\frac{c_{1} c_{2}^{2} V^{2}}{6}}=3 \cdot \sqrt[3]{\frac{c_{3} V^{2}}{6}}=c_{4} V^{\frac{2}{3}} \\
& c_{4}=\sqrt[3]{\frac{27 c_{3}}{6}}=\frac{A_{1}}{V_{1}^{2 / 3}}
\end{aligned}
$$

The coefficient of determination between the pyramid approximation and the actual areavolume relationship on the tested reservoirs averaged 0.983 , with the worst fit of 0.911 in Lake Nasser. In addition, the pyramid approximation has the advantage that it has only one parameter and therefore requires only one data point of area and volume. Normal storage volume and area are often included in reservoir databases, which will provide the necessary information for applying the pyramid approximation.

For multiple reservoirs, either a linear approximation or the pyramid approximation can be used to estimate the aggregate area-volume relationship. The linear approximation is fitting a line through the origin of zero volume and zero area and the total of all the reservoir volumes and their corresponding surface areas. In the case of multiple reservoirs, however, the operating policy or policies for the reservoirs play an important 
role in determining the combined surface area of the reservoirs at any point in time. Different operating policies from maximizing head to minimizing surface area result in a range of area and volume relations between which the combined reservoirs could fall within. The pyramid approximation may give a more conservative estimate of evaporation, i.e. greater evaporation, for planning purposes since it falls at the higher side, or greater surface area portion of this range. It may also be a more accurate estimate than a linear approximation especially if the reservoirs are operated independently. A linear approximation for the area-volume relationship to the maximum area and volume point of the combined reservoirs falls more in the center of the range. Familiarity with the reservoir system and the particular issue being investigated can determine which is more appropriate on a case-by-case basis. Both produce only estimates and the actual area and volume point at any particular time could be somewhat different from the estimate.

The greatest uncertainty is introduced in approximating the aggregate area-volume relationship for a large watershed where no existing storage area and volume data are available. In this case, the best estimate may be to apply the average slope of the linear area-volume relationship in watersheds of similar size. The estimate can be improved greatly if an area-volume point is available at one or more reservoirs in the watershed. The area-volume line can then be extrapolated from the total known area and volume. This will still produce considerable error; the more reservoirs with an area-volume point, the less the error. Because so much water can be lost to evaporation in arid regions, an approximate estimate of evaporation is more accurate than completely ignoring evaporation.

\subsection{Evaluating Importance of Spatial Scale in River Basin Modeling: Case Study of Missouri River Basin}

To evaluate the importance of scale on river basin modeling, the Missouri River Basin (area of 1.3 million square kilometers) in the mid-western USA was taken as a case study. The Missouri River Basin is an excellent case study because it represents a basin where spatial scale is very important. The basin is wet in the north and dry in the south. The majority of irrigation occurs in the middle of the basin. Therefore, spatial details are important because water is not necessarily available where it is needed. A model previously developed by Hurd et al. (1998) was used as a starting point for this analysis. The model was developed using the programming language GAMS (General Algebraic Modeling System). GAMS is best known for its use in economic modeling and has recently proven to be very useful in tackling combined water resources and economic modeling issues.

The model represents the Missouri River Basin by including the main stem of the Missouri River, the Kansas River, the Platte River, and the Osage River. There are 13 nodes on the Missouri, 4 nodes on the Kansas, 4 nodes on the Platte, and 2 nodes on the Osage. Floodwater is modeled on eight of the river nodes. Hydropower production occurs at three of the river nodes while two of the nodes have minimum flow requirements. Water withdrawals are divided into three categories; agriculture, municipal, and thermal and these are modeled at 6 of the river nodes. Non-consumptive water users include 
hydropower, navigation, flood control, water quality, and waste assimilation. Four reservoirs throughout the river system and eight inflow sources are also modeled.

By weighing the economic tradeoffs between alternative water uses, the model determines the most efficient allocation and storage of water given the watershed's economic and physical characteristics, and a given sequence and spatial pattern of runoff. A seasonal time-step simulates the inflow and movement of water throughout the river basin.

The economic data in the model were first aggregated using average values for price, slope, etc. This was found to have little impact on the results. This is a very useful result because it supports the idea of applying regional economic data at a smaller scale.

Next the hydrology and water management data were aggregated to represent one inflow, one reservoir, one withdrawal node (still aggregated into agriculture, municipal, and thermal,) one navigation node, one flood damage threshold, one minimum flow requirement, one waste assimilation site, one water treatment site, one thermal pollution site, and one hydropower site.

By aggregating the data, demands are allowed to pull their water from anywhere in the Missouri Basin. This is obviously a false representation of the basin, but our question is "Does it matter?" For most climate change analyses, flows will vary, but not necessarily as low as consistently half the historical flow. The various components of the objective function with the exception of thermal pollution, flood damage, waste assimilation, and navigation (instream flows) are affected the most by very low flows when comparing the results of modeling the disaggregated Missouri Basin to the aggregated basin. Thus it is reasonable to simplify climate change models by aggregating data in basins noting that aggregation tends to overestimate water available for non-instream demands at low flows. Thermal pollution, flood damage, navigation, and waste assimilation are difficult to aggregate because of their dependency on spatial location. Further research is necessary to represent these aggregated nodes in a more realistic manner.

\subsection{Related Implementation Activities Resulting from Project}

1. As a result of this project, the Joint Global Change Research Institute (JGCRI) and IFPRI have started discussing the process to link MIINCAM/SGM with IMPACTWATER.

2. The project results are being incorporated into WATERSIM, the next generation of the IMPACT WATER model of IWMI and IFPRI.

3. Presentations at Snowmass in 2000-2003 have lead to international transfer of results.

4. At least 7 journal papers are in preparation - one from each of Sections 2 through 8 
5. The results of the gridded WATBAL application have been used in a World Bank GEF study on climate, water and agriculture in Africa.

\section{Acknowledgements}

Although the research described in this report has been funded by the Office of Energy

Research of the U.S. Department of Energy under Grant Number DE-FG02-98ER62665 to Tufts University, it has not been subjected to the Department's peer and policy review and does not necessarily reflect the views of the Department. We appreciate the support of the Office of Energy Research and also acknowledge the helpful research discussions we have had with Richard Vogel, William Fernandez, James Limbrunner, and A.

Sankarasubramanian.

\section{References}

Buishand, T.A, T. Brandsma, 2001. Multisite Simulation of Daily Precipitation and Temperature in the Rhine Basin by Nearest-Neighbor Resampling, Water Resour. Res., $37(11), 2761-2776$.

Dunne, K.A. and C.J. Willmott, 1996. Global Distribution of Plant-Extractable Water Capacity of Soil. International Journal of Climatology, 16, 841-859.

Fischer, G., K. Frohberg, M.A. Keyzer and K.S. Parikh, 1998. Linked National Models A Tool for International Food Policy Analysis, Kluwer Academic Publishers.

Hurd, B., M. Callway, J. Smith, and P. Kirshen, 1998. Economic Effects of Climate Change on US Water Resources, Chapter 6 of Economic Impacts of Climate Change on the US, Mendelsohn, R. and Neumann, J., editors, Cambridge University Press, 1998.

Lall, U., and A. Sharma,1996. A Nearest Neighbor Bootstrap for Time Series Resampling, Water Resour. Res., 32(3), 679-693.

Löf, George O. G. and Clayton H. Hardison, 1966. Storage Requirements for Water in the United States, Water Resources Research, vol. 2, no. 3 (Third Quarter 1966), pp. 323354.

New, M. G., M. Hulme and P. D. Jones, 2000. Twentieth-Century Space-Time Climate Variability. Part II: Development of 1901-1996 monthly grids of terrestrial surface climate. J. Climate, 13, 2217-2238.

Rajagopalan, B., U. and D. Lall, 1999. A K-Nearest Neighbor Simulator for Daily Precipitation and Other Variables, Wat Res. Res., 35(10), 3089-3101.

Root, T.L., and S. Schneider. 1995. Ecology and Climate: Research Strategies and Implications, Science, 269 (5222), July 21. 
Rosegrant, M., W.M. Agcaoili-Sombilla and N. Perez, N., 1995. Global food projections to 2020: Implications for Investment. Food, Agriculture, and the Environment, Discussion Paper 5. International Food Policy Research Institute, Washington D.C.

Rosenzweig, C., and M. L. Parry. 1994. Potential Impact Of Climate Change On World Food Supply, Nature, Vol. 367, pp. 133- 138.

Viner, D., 2000. The Climate Impacts LINK Project, Climate Data for the International Climate Change Research Community, http://www.cru.uea.ac.uk/link/index.htm, University of East Anglia, United Kingdom.

Wollman, Nathaniel and Gilbert W. Bonem, 1971. The Outlook for Water: Quality, Quantity, and National Growth. John Hopkins Press, Baltimore and London.

Yates, D., 1996. WatBal: An Integrated Water Balance Model for Climate Impact Assessment of River Basin Runoff, International Journal of Water Resources Development, 12(2).

Yates, D.N. and K.M. Strzepek, 1998. An Assessment of Integrated Climate Change Impacts on the Agricultural Economy Of Egypt, Climatic Change, 38(3), 261-287. 